\title{
Mechanisms of protein misfolding: Novel therapeutic approaches to protein-misfolding
} diseases

Salahuddin, Parveen; Siddiqi, Mohammad Khursheed; Khan, Sanaullah; Abdelhameed, Ali Saber; Khan, Rizwan Hasan

Published in:

Journal of Molecular Structure: THEOCHEM

Link to article, DOI:

10.1016/j.molstruc.2016.06.046

Publication date:

2016

Document Version

Peer reviewed version

Link back to DTU Orbit

Citation (APA):

Salahuddin, P., Siddiqi, M. K., Khan, S., Abdelhameed, A. S., \& Khan, R. H. (2016). Mechanisms of protein misfolding: Novel therapeutic approaches to protein-misfolding diseases. Journal of Molecular Structure:

THEOCHEM, 1123, 311-326. https://doi.org/10.1016/j.molstruc.2016.06.046

\section{General rights}

Copyright and moral rights for the publications made accessible in the public portal are retained by the authors and/or other copyright owners and it is a condition of accessing publications that users recognise and abide by the legal requirements associated with these rights.

- Users may download and print one copy of any publication from the public portal for the purpose of private study or research.

- You may not further distribute the material or use it for any profit-making activity or commercial gain

- You may freely distribute the URL identifying the publication in the public portal 
Mechanisms of protein misfolding: Novel therapeutic approaches to proteinmisfolding diseases

ParveenSalahuddin $^{1}$, Mohammad Khursheed Siddiqi ${ }^{1}$, Sanaullah Khan ${ }^{2}$, Ali Saber Abdelhameed $^{3}$, Rizwan Hasan Khan ${ }^{1 *}$

${ }^{1}$ DISC, Interdisciplinary Biotechnology Unit, A.M.U.Aligarh-202002, India

${ }^{2}$ Department of Micro- and Nanotechnology, Technical University of Denmark, ØrstedsPlads, building 345B, DK-2800 Kgs.

${ }^{3}$ Department of Pharmaceutical Chemistry, College of Pharmacy, King Saud University, P.O. Box 2457, Riyadh 11451, Saudi Arabia

Corresponding Author*

Rizwan Hasan Khan

Interdisciplinary Biotechnology Unit

Aligarh Muslim University,

Aligarh 202 002, India

Telefax: +91-571-2721776

E-mail: rizwanhkhan@hotmail.com

rizwankhan1@gmail.com 


\begin{abstract}
In protein misfolding, protein molecule acquires wrong tertiary structure, thereby induces protein misfolding diseases. Protein misfolding can occur through various mechanisms. For instance, changes in environmental conditions, oxidative stress, dominant negative mutations, error in post-translational modifications, increase in degradation rate and trafficking error. All of these factors cause protein misfolding thereby leading to diseases conditions. Both in vitro and in vivo observations suggest that partially unfolded or misfolded intermediates are particularly prone to aggregation. These partially misfolded intermediates aggregate via the interaction with the complementary intermediates and consequently enhance oligomers formation that grows into fibrils and proto-fibrils. The amyloid fibrils for example, accumulate in the brain and central nervous system (CNS) as amyloid deposits in the Parkinson's disease (PD), Alzheimer's disease (AD), Prion disease and Amylo lateral Sclerosis (ALS). Furthermore, tau protein shows intrinsically disorder conformation; therefore its interaction with microtubule is impaired and this protein undergoes aggregation. This is also underlying cause of Alzheimers and other neurodegenerative diseases. Treatment of such misfolding maladies is considered as one of the most important challenges of the $21^{\text {st }}$ century. Currently, several treatments strategies have been and are being discovered. These therapeutic interventions partly reversed or prevented the pathological state. More recently, a new approach was discovered, which employs nanobodies that targets multisteps in fibril formation pathway that may possibly completely cure these misfolding diseases. Keeping the above views in mind in the current review, we have comprehensively discussed the different mechanisms underlying protein misfolding thereby leading to diseases conditions and their therapeutic interventions.
\end{abstract}

Keywords Protein-misfolding, Dominant-negative mutations, Amyloid, Oxidative Stress, Error in post-translational modifications, Error in trafficking, Therapeutic approaches to protein misfolding diseases 


\section{Abbreviations}

A $\beta \quad$ Amyloid beta peptide

APP Amyloid Precursor Protein

AD Alzheimer's disease

AGEs Advanced Glycation End Products

ALS AmyloLateral Sclerosis

CNS Central nervous system

DM Diabetes Mellitus

DBD DNA-binding Domain

ER Endoplasmic Reticulum

ERAD Endoplasmic-Reticulum-Associated protein Degradation

ECMs Extracellular Membranes

FDAP Fluorescence Decay After Photoconversion

GAGs Glycosaminoglycans

GSK-3 Glycogen Synthase Kinase-3

HA Hyaluronic Acid

HS HeparanSulfate

JNK c-Jun N-terminal Kinase

LB Lewy bodies

NFTs Neurofibrillary Tangles

PD Parkinson's Disease

PDI Protein Disulfide Isomerase

PGs Proteoglycans

PrP Prion protein

PTMs Post Translational Modifications

RAGE Receptor for AGE

ROS Reactive Oxygen Species 


\section{Introduction}

Protein misfolding occurs because of several factors including, dominant-negative mutations, changes in environmental conditions $(\mathrm{pH}$, ionic strength, temperature, and protein concentrations), error in post-translational modifications, increase degradation rate, oxidative stress and error in trafficking. Such factors may act either independently or simultaneously [1]. Various experiments (in vitro and in vivo) suggest that misfolded or partially unfolded intermediates are particularly liable to aggregation, especially at high peptide concentrations [26]. These partially unfolded or misfolded intermediates are enhanced under equilibrium conditions. The partially unfolded intermediates contain large patches of adjoining surface hydrophobicity, hence they can aggregate more easily than native and unfolded proteins, which possess hydrophobic amino acid situated at the interior core of protein and lie scattered in the polypeptide chain, respectively. These partially unfolded intermediates tend to aggregate by interacting with complementary intermediate and consequently enhance oligomers formation which grows into proto-fibrils and fibrils (Fig.1). The amyloid fibrils are important origins of toxicities that led to diseases conditions such as amyloidosis. The amyloid fibrils characteristically composed of 2-6 unbranched protofilaments with a diameter of 2-5 $\mathrm{nm}$ which is linked laterally or twisted together forming fibrils with diameters of 4-13 nm [7-9]. The fibrillar aggregates can interact with dyes such as Congo red leading to birefringence as well as thioflavin$\mathrm{T}$ resulting in fluorescence.

Initial studies have shown that amyloid fibrils were the main culprit behind toxicity that led to neurodegenerative diseases. However, currently attention shifted to the cytotoxicity of amyloid fibril precursors, notably amyloid oligomers, which are the major reason of toxicity. Molecular 
mechanisms that induce the formation or stabilization of oligomers of the wild-type $A \beta$ remain unclear. In our earlier review [10] we have discussed that there are several mechanisms of toxicities caused by oligomers. Later on, in our review we have hypothesized two major possible mechanisms of toxicities instigated by oligomers of $\mathrm{A} \beta$ (amyloid beta), $\operatorname{PrP}$ (prion protein) (106-126, and $\alpha$-Syn (alpha-synuclein) including direct formation of ion channels and neuron membrane disruption by the increase in membrane conductance or leakage in the presence of small globulomers to large prefibrillar assemblies This is also validated by most recent findings that showed oligomer-related toxicities including : nonspecific perturbance of cellular and intracellular membranes and amyloid pore channel formation[11].

Intrinsically disorder conformation of tau is also important origin of different neurodegenerative diseases. Since tau protein adopts intrinsically disorder conformation therefore its interaction with microtubule is impaired and it undergoes aggregation leading to Alzheimer's diseases and several other neurodegenerative diseases Using predictive atomic resolution descriptions of intrinsically disordered hTau40 and $\alpha$-synuclein in solution from NMR and small angle scattering, enhanced polyproline II sampling occurred in aggregation-nucleation sites, supporting the suggestions that this region of conformational space plays an important role in aggregation [12]. Furthermore, majority of all prolyl bonds in the functional TauF4 fragment exist in the trans conformation [13]. Phosphorylation does not change this conformational state. Since, pThr231-Pro232 prolyl bond of Tau in Alzheimer's disease neurons is dominantly in the trans conformation, this challenges the recent concept of "cistauosis" [14] 
Previous attempts have largely failed to analyze the structure of tau in complex with MTs. This is because of the mobility of the Tau structure and the dynamic nature of Tau-MT interaction. Now the molecular insights into the interaction between Tau and MTs and tau aggregation have been solved to some extent. The data showed that although intrinsically disorder tau exists as largely extended state. When bound to the MT at the interface $[15,16]$, it does not fold into a globular structure but rather distinct regions of Tau fold into well define hairpin structure upon binding which is formed around the PGGG motif[17]. Huang and Stultz, have demonstrated that aggregation promoting sequence or motif, $\mathrm{PHF6}^{*}$, prefers an extended conformation in both wild type and K280 mutant besides this residue K280 adopts loop turn conformation in WT MTBR2 and deletion of this residue led to an increase in locally extended conformation near the C-terminus of PHF6*. An increased propensity for extended state near terminus of PHF6* may facilitate tau aggregation. These results explain how a deletion at position 280 can promote the formation of tau aggregate [18].

Deeper insight into the tau-microtubule interactions have also been provided by FDAP analysis [19]. The data showed that tau-microtubule dynamics differ in vitro and in vivo. In particular, it was shown that diffusion of bound tau was negligible in vivo contrary to the findings that tau diffuses along MT lattice in vitro [19].

One of the important mechanisms of misfolding is the occurrence of dominant negative mutation. For instance, mutation in the insulin results in misfolding hence produce Diabetes Mellitus (DM) disease [ 20-23]. In the endoplasmic reticulum (ER) of pancreatic $\beta$-cells, these mutations ensue toxic misfolding in proinsulin's molecule [24, 25]. In a similar vein, changes in 
the environmental conditions (temperature, $\mathrm{pH}$, ionic strength and protein concentration) results in the formation of misfolded proteins which has high propensity to aggregate and cause misfolding diseases e.g. neurodegenerative diseases. Post-translational modifications error (glycation, phosphorylation, and sulfation) is another mechanism that may instigate misfolding diseases. However, phosphorylation itself is not an error, but is vital for many biological processes.

Glycation, promotes aggregation, consequently cross-linking of fibril occurs leading to diseases conditions [26]. This is validated by the findings that glycation aggravated neurotoxicity [27]. Likewise, phosphorylation promotes aggregation by forming oligomeric $A \beta$ species, which act as nuclei for fibrillization [28]. These soluble small oligomers undergo conformational transition from $\alpha$-helical and random coiled states to a $\beta$-sheet structure [28]. The tau protein was also shown to be peculiarly hyper-phosphorylated at differentSer/Thr residues in $\mathrm{AD}$, which led to the buildup of neuro-filament sub-units in the AD brain [29,30]. Sulfation plays a crucial role in amyloid formation. It promotes formation of insoluble amyloid fibrils through aggregation of $A \beta$, which adds to the increased neurotoxicity of $A \beta$. Despite of the fact that Abetas readily selfaggregate in vitro forming amyloid fibrils, their interaction with proteoglycan sulfate further accelerate amyloid aggregation and fibril formation [31]. Increased protein degradation rate also directs to misfolding diseases [32]. A typical example is provided by the cystic fibrosis, which result from the removal of Phe at amino acid position 508 in cystic fibrosis transmembrane regulator protein. This mutation led the protein to misfold rendering it as a target for degradation [33]. Error in trafficking may induce dysfunction through loss of protein function at appropriate site or gain of toxic function if it accumulates at incorrect site. For instance, mutation in $\alpha-1$ - 
antitrypsin leads to lungs diseases including emphysema because of losing the function at this site, and liver diseases by a gain of toxic function because mutant form of this protein fails to complete proper folding hence accumulate in the ER of hepatocytes leading to liver damage [34]. Similarly, oxidative stress is involved in the pathogenesis of neurodegenerative diseases such as $\mathrm{AD}$, which is characterized by the deposition of intracellular aggregates that contains typically phosphorylated forms of the tau protein [35]. Thus, these mechanisms provide important therapeutic interventions. In views of above, in the current review we shall comprehensively discuss the underlying mechanisms of protein misfolding that lead to diseases conditions and their therapeutic interventions.

\section{Protein misfolding mechanisms}

When proteins such as cystic fibrosis transmembrane regulator, amyloid beta, Parkin, and Prp misfold, it gives rise to different pathological states including cystic fibrosis, Alzheimer's disease, Parkinson's disease and Prions disease respectively. The mechanism of misfolding and thereby associated diseases occur by several mechanisms, some of them are discussed below:

\section{Changes in environmental conditions}

The rate and extent of amyloid formation is greatly dependent upon the environmental conditions including changes in ionic strength, $\mathrm{pH}$, temperature, and protein concentration. Recent results showed that $\mathrm{pH}$ affected both fibrils formation and their morphology [36]. For instance, extracellular P-(1-28) segment displayed clear $\mathrm{pH}$ dependence fibrils formation profile. The $\mathrm{pH}$ dependent fibrils formation showed that at low $\mathrm{pH}(2.5)$, fibrils fragments were formed with 60$80 \AA$ diameter and several hundred angstroms in length. Increasing the $\mathrm{pH}$ to 5.5 led to 
generation of numerous large non-branched fibrils with similar diameters. These fibrils at $\mathrm{pH} 8$ were mostly converted into amorphous materials, which are often found lightly stained [36]. In a similar vein, aggregation of beta amyloid protein $(\mathrm{A} \beta 1-42)$ is strongly dependent on the $\mathrm{pH}$ of the solution [37].The Abeta (1-42) peptides formed large and complex fibrillar structure with higher efficiency under acidic condition than at neutral $\mathrm{pH}[37]$. Furthermore, Abeta aggregates caused significant apoptotic death of PC12 cells only at $\mathrm{pH}$ 5.8. Thus, it is proved that the A betas present in acidic organelles could form neurotoxic fibrils much more readily than in the neutral cellular compartments [37].

Similarly, changes in ionic strengths have profound effect on aggregation kinetics of amyloid $\beta$ peptide. This was validated by molecular dynamic studies by several authors [38-40] that increase in ionic strength enhanced the atomic fluctuation of the hydrophobic core [38-40] with decline in the stability of the beta-sheet structure (which are mainly stabilized by internal hydrogen bonds). This implies that amyloid beta has high aggregation propensity at high ionic strength with strong propositions in $\mathrm{AD}$.

Studies have demonstrated that temperature also has an important role in the aggregate formation [41]. For instance, at different temperatures transition of solid Abeta (1-28) and Abeta (1-40) peptides, from $\alpha$-helix to beta-sheet structure, occurred near $40^{\circ} \mathrm{C}$ and $45^{\circ} \mathrm{C}$ respectively. These peptides have significant aggregation tendency. However, no transition temperature for solid Abeta (1-42) peptide occurred because it already exists as beta-sheet structure. In fact this peptide (Abeta(1-42)) does not contain alpha-helix and random coil structures but contain only beta sheet structure, hence it has high aggregation propensity. These results suggest that 
temperature can also influence the $\mathrm{A} \beta$ aggregates formation which possibly may have implications in AD.

Similarly, the high concentration of $\mathrm{A} \beta$ peptide may as well affects $\mathrm{AD}$. This was demonstrated by recent study that showed elevated levels of A $\beta$ in CSF, which may be an index of age-related changes in the processing of the amyloid precursor protein leading to a high risk for AD [42].

\section{Dominant negative mutations, loss of function and gain of toxic function}

Dominant negative mutations are important origins of protein misfolding thereby leading to conformational diseases. For instance, mutations in the insulin gene produced DM disease [43$45,24]$. These mutations resulted in proinsulin toxic misfolding in the pancreatic $\beta$-cells [46, 47]. Mutations occur in all regions of pre-proinsulin including signal peptide and A, B, C domains. Most of these mutations initiate addition or removal of cysteine thus enhances odd number of potential pairing sites. Therefore, formation of wrong pairing of disulfide bonds occur hence causes misfolding and aggregation [46-48]. Remarkably, several human mutations encodes the similar "Akita" substitution (Cys A7 Tyr) as in the Ins2 gene of Mody4 mouse [4951].The variant murine proinsulin in vitro also goes through partial unfolding with increase formation of aggregate [52]. Similar perturbations have also been found in human insulin and proinsulin analog lacking Cys A7-B. Further, heterozygous expression of variant Ins2 allele encoding Cys A6 to Ser mutation resulted in DM.

Another instance for dominant-negative mutation is the misfolding of homotetrameric transcription factor p53 that predisposes individuals with diseases conditions $[53,54]$. The p53 is a tetrameric nuclear phosphoprotein that has an important role in preventing cancer diseases [53]. 
The p53 enhances cell-cycle arrest or apoptosis in response to stress signals including DNA damage. Disruption of the p53 network has adverse consequences that favor cell survival and tumour progression [54-57]. The p53 is mainly regulated by the ubiquitin ligase Mdm2 (murine double mutant 2), which binds p53 and targets it for degradation by the proteasomal machinery [58]. The human p53 protein comprises 393 amino acid residues which are organized into three domains: the N-terminal activation domain interacts with various proteins; the CTD is accountable for tetramerization; and the core domain (p53C) encompassing residues 94-312 forms DNA-binding domain (DBD) [59,60]. Over 90\% of p53 dominant negative mutations are associated with diseases conditions are found in the DBD [61]. The p53 aggregation into amyloid oligomers and fibrils has already been demonstrated by Silva et al. (2014) [62]. Furthermore, the amyloid aggregates of both the mutant and WT (wild-type) forms of p53 have been identified in tumor tissues $[63,64]$.

\section{Error in post-translational modifications}

Normally enzymatic post translational modifications (PTMs) are highly controlled processes and play an important role in many cellular processes; however, under stressed or diseased conditions this regulation can be ineffective [65]. When enzymatic PTMs lead to excessive or differential modifications they increase the propensity of protein to form aggregate [66]. Examples of enzymatic PTMs that play crucial role in protein misfolding and aggregation are glycation, sulfation, and phosphorylation [67-70]. 


\section{Glycation}

Recently, great interest was shown in the role played by non-enzymatic protein glycation in inducing amyloid aggregation and toxicity. Proteins in amyloid deposits are often found glycated signifying a direct link between amyloidosis and protein glycation [70-76]. Earlier reports have demonstrated that $A \beta$ is a suitable substrate for glycation resulting in the formation of advanced glycation end products (AGEs). Now accumulating evidence shows that $\beta$-amyloid (A $\beta$ ) is neurotoxic and its accumulation is responsible for the manifestation of Alzheimer's disease (AD). However, it is yet not clear how $\mathrm{A} \beta$ accumulates and affects toxicity. Now researchers have found that $\mathrm{A} \beta$-AGE formation can aggravate the neurotoxicity of simple $A \beta$ with up regulation of receptor for AGE (RAGE) and activation of glycogen synthase kinase-3 (GSK-3) [27]. The protein glycation has also been considered as an age related phenomenon that affects mainly extracellular proteins including collagen and elastin, which provides mechanical strength and flexibility to the tissues. AGEs formation also induce development of covalent cross-links among proteins (Fig.3). This process is gradual; therefore, cross-links stack on the long run on the oldest extracellular proteins like elastin and collagen, which are not removed by proteasomal machinery [76]. Most recently differential effect of glycation on the aggregation of proteins and amyloid formation was observed [75].The results showed that glycation depended on both the nature of protein molecule as well as glycating agent. In fact, some glycated proteins go through oligomerization with no promotion of the amyloid fibril formation.

Glycation of $\alpha$-synuclein ensues the development of toxic aggregate, which ultimately causes Parkinson's disease and Lewy bodies (LB) formation. Glycation was primarily shown to be located in substantia nigra and locus coeruleus of peripheral LB [76].Lee et al. (2009) [77] have 
found that methylglyoxal induces oligomerization of $\alpha$-synuclein but prevents amyloid fibrils formation. Additionally, protein fibrillization was nearly completely inhibited by seeding with modified $\alpha$-synuclein. Similarly, D-ribosylation of $\alpha$-synuclein promotes molten globule-like aggregates formation, which, produced oxidative stress and caused high cytotoxicity to the cells [78].

\section{Phosphorylation}

Recently, studies [29] have shown that extracellular $A \beta$ goes through phosphorylation by protein kinase A either as a cell surface-localized or secreted form. The phosphorylation of serine residue 8 induces oligomeric $A \beta$ aggregates formation that eventually undergoes fibrillization (Fig.4). These small soluble oligomers undergo conformational transition from $\alpha$-helical and random coiled states to $\beta$-sheet structure, as proved by their circular dichroism spectra [28]. The phosphorylated $A \beta$ also accumulate with aging. This was established by phosphorylation-state specific antibodies that showed the occurrence of phosphorylated $A \beta$ in murine $A D$ models and in the brain of $\mathrm{AD}$ patient's. Remarkably, these antibodies proved that phosphorylation takes place favorably at free extracellular A $\beta$ rather than at the full-length APP or $\beta$-CTF, the precursors of $A \beta$ peptide. These phosphorylated $A \beta$ are co-found with non-phosphorylated $A \beta$ in extracellular plaques [30]. Phosphorylated A $\beta$ was identified at the age of 2 months in APP transgenic mice. Consequently, phosphorylation of $\mathrm{A} \beta$ may possibly be pertinent in the pathogenesis of late onset $\mathrm{AD}$. Recently, it has been shown that phosphorylation of the amyloid $\beta$-peptide at Ser26 stabilizes oligomeric assembly and increases neurotoxicity [79]. 
Tau is a microtubule-associated protein, responsible for the assembly and stability of microtubule in the neuronal cell and for axoplasmatic transport. Tau was shown to be atypically hyperphosphorylated at several Ser/Thr residues in $\mathrm{AD}$ and thereby detaches from axonal microtubules and aggregates into insoluble NFT [30, 80]. However, the pathophysiological mechanism of tau phosphorylation is still a debatable issue.

\section{Sulfation}

Recently, Ariga and co-workers [31] have demonstrated that binding of A $\beta$ to extracellular membranes (ECMs) is a critical step in the development of AD. A $\beta$ also binds to many other biomolecules such as lipids, proteins, and proteoglycans (PGs). PGs play an important role in amyloid formation (Fig.4). It promotes aggregation of $\mathrm{A} \beta$ into insoluble amyloid fibrils that adds to the neurotoxicity of $A \beta$. Even though Abetas freely self-aggregate to yield amyloid fibrils in vitro, their interaction with PGs and heparan enhanced amyloid aggregation and fibril formation. The glycosaminoglycans (GAGs) sulfate moiety, the carbohydrate portion of PGs, play an important role in the amyloid fibrils formation [81]; no fibrils are formed in the presence of hyaluronic acid (HA), a non-sulfated GAG. PGs and A betas co-localize in senile plaques (SPs) and neurofibrillary tangles (NFTs) in the AD brain. The 13-16-amino-acid region (His-His-GlnLys) of PGs binds to Abetas and serves a distinctive target site for the prevention of the formation of amyloid fibril; His13 in particular is an important residue critical for the binding to GAGs.

Glycosaminoglycans (GAGs) are also present in $\operatorname{PrP}(\mathrm{Sc})$ deposits. In vitro $\operatorname{PrP}(\mathrm{C})$ misfolding was enhanced by GAGs. They are co-found in cellular compartments with $\operatorname{PrP}(\mathrm{C})$ and were 
suggested to be disease modifying in vivo. Most recently, the effects of sulfated GAGs, heparan and heparan sulfate (HS), on disease associated misfolding of full-length recombinant PrP were studied [82]. Heparan and HS induced a $\beta$-sheet conformation in recombinant PrP that became aggregated; however, the aggregates produced in the presence of heparan or HS have different solubility and protease resistance properties. Thus, minor alterations in the physico-chemical characteristics of prion disease cofactors may initiate protein misfolding.

\section{Proteolytic cleavage}

Proteolytic cleavage also leads to protein misfolding thereby neurodegenerative diseases [66, 67]. A sequence of proteolytic cleavages occurring in the amyloid precursor protein (APP) resulted in the formation of different length of $A \beta$ peptides (Fig.2). In this regard, the last cleavage is catalyzed by $\gamma$-secretase (E.C.3.4.23), which can cleave at various amino acid positions of APP including 38, 40 and 42. Of these, the A 342 fragment showed the highest tendency to build up toxic oligomers. Such example and others suggest a role of proteolytic cleavage in triggering amyloid formation [66].

\section{Error in degradation}

Error in cellular degradation systems including ERAD or autophagy is one mechanism that raises the concentration of not only fully folded proteins but also misfolded and toxic proteins. Conversely, in addition to promoting the removal of toxic and pathology associated misfolded and aggregated proteins, activating the degradation system can results in the removal of proteins critical for the normal function and survival. Thus, improper degradation of protein can contribute to the development of more severe diseases. A typical example is provided by the 
cystic fibrosis, which occurs because of deletion of Phe at amino acid position 508 in cystic fibrosis transmembrane regulator protein. This mutation triggers protein misfolding thereby it is targeted for degradation [83], thus ensues disease because of lack of this protein.

Another instance for protein misfolding disease caused by error in degradation system is provided by Gaucher's disease's which is the most widespread form of lysosomal storage diseases $[84,85]$. Gaucher's disease occurs because of mutations in $\beta$-glucosidase that result in misfolding, accumulation of aggregated protein specifically in the leukocytes which are not cleared by cellular degradation machinery thus initiate toxicity and disease conditions.

\section{Error in trafficking}

For proteins to be present in particular organelles they must fold correctly. Hence, mutations that destabilize the correctly folded protein may lead to incorrect subcellular localization. This may cause dysfunction through two mechanisms including loss of protein function at appropriate site and acquisition of toxic function if it accumulates at incorrect site. The main example of this type of mutation is $\alpha-1$ - antitrypsin which, when mutated culminates in emphysema due to the loss of function, and liver diseases by a dominant acquisition of toxic function because the mutant protein fails to establish proper folding, hence they are retained in the ER of the hepatocytes causing liver damage [34]. Moreover, because mutated protein is not secreted into bloodstream, hence it is unable to inhibit serine protease including neutrophil elastase in the lungs leading to extensive destruction of the lung's connective tissue which culminates into emphysema. 


\section{Amyloid accumulation}

Amyloid fibers are insoluble fibrous protein aggregates, which accumulate and contribute to a variety of different neurodegenerative diseases including $\mathrm{AD}$, Parkinson's disease and Huntington's disease as well as amyloidoses such as familial amyloid polyneuropathy and primary systemic amyloidosis [86-88]. Currently, small oligomers are believed to be more responsible for disrupting cellular function. On the contrary, it has been proposed that amyloid deposits could have protective function because it can sequester these toxic species [89]. However, it is noted that amyloid itself can spread disease from neurons to neurons perhaps causing more havoc [90-92].

\section{ER Stress and Oxidative Stress in Neurodegenerative Diseases}

Oxidative stress and protein misfolding are associated with the pathogenesis of neurodegenerative diseases [93] including AD, PD, that are distinguished by fibrillar aggregates composed of misfolded proteins [94]. At the cellular level, oxidative stress and ER stress or both may mediate neuronal death or apoptosis. Upregulation of ER stress and their markers have been detected in the post-mortem brain tissues and cell culture models of many neurodegenerative disorders including PD, AD, amylolateral sclerosis(ALS) and expanded polyglutamine diseases e.g. Huntington disease and spinocerebral ataxias [95]. Latest reports show that oligomeric forms of polypeptides maybe the most toxic form that caused neuronal death. However, the role of these oligomeric species in ER function and ROS generation is currently not understood.

Oxidative stress is involved in the pathogenesis of neurodegenerative diseases such as AD which is characterized by the deposition of intracellular aggregates containing abnormally 
phosphorylated forms of the microtubule binding protein Tau[35].Using a drosophila model of $\mathrm{AD}$ it was shown that oxidative stress plays a crucial role in neurotoxicity by promoting tau phosphorylation. Further, in such model of activation the JNK pathway correlated with the degree of tau-induced neurodegeneration [96]. Although oxidative stress and ER stress have been associated to neurodegenerative diseases but to-date it has not been possible to confirm that these processes are the principal causes of neurons death. However, these stresses have been reported to alter the evolution and severity of such complex diseases.

PD is considered as the second most common neurodegenerative disease which is distinguished by the dopaminergic neurons loss. Analysis of familial Parkinson disease revealed involvement of three genes encoding $\alpha$-synuclein, Parkin and ubiquitin C-terminal esterase L1 (UCH-L1). $\alpha$ synuclein is a cytoplasmic protein that forms aggregate called Lewy bodies that are characteristic for Parkinson's disease; however, the link between $\alpha$-synuclein and ER stress is currently not understood. Parkin is an ubiquitin protein ligase (E3) (EC 6.3.2.19) involved in ERAD [96]. However, the expression of parkin is induced by ER stress [96]. These observations suggest the involvement of ER stress in PD. Additionally; several more studies suggest the relation between ER stress and PD. Firstly, PD mimetics e.g. 6-hydroxydopamine specifically prompt ER stress in neuronal cells [97]. Secondly, expression of ER chaperones is upregulated in the brain of PD patients and PDI is accumulated in Lewy bodies [98]. The observation of PDIp, a homologue of PDI, in experimental PD and Lewy bodies suggest that oxidative protein folding in ER may possibly be disturbed in PD.

\section{Therapeutic strategiesto protein misfolding diseases}


Numerous sporadic and genetic diseases occur mainly due to protein misfolding. To treat these devastating disorders is a great challenge. Some of the therapeutic interventions are described below.

\section{Manipulation of environmental factors for regulating protein misfolding diseases}

By modulating environmental conditions, aggregation of amyloid beta protein and their associated diseases can be avoided. For instance alkaline $\mathrm{pHs}$ are most far away from the PI of Abeta, which means that the average deprotonation state of carboxylates is greatest relative to the average protonation states of amines or imines at low $\mathrm{pH}$. Therefore, charge repulsion would be expected to interfere with intra- and inter-molecular interactions and thereby escort monomeric protein to fold and assemble [99]. Similarly, a rise in the ionic strength increase the atomic fluctuation of the hydrophobic core of beta-sheet thereby it decreases the amount of Abeta aggregate. Further, elevated temperature (such as fever) can also give rise to structural alterations in $A \beta$ (tangles and plaques) or change the brain characteristic identical to those observed in $\mathrm{AD}[100]$. This study provides important therapeutic interventions.

Researchers have discovered various proteins called secretases: BACE-1(EC 3.4.23.46), BACE2(EC 3.4.23.45) and gamma secretase (E.C.3.4.23) [101-105] are involved in cutting APP into beta-amyloid. Changing the cutting behavior of such proteins may inhibit or reduce beta-amyloid development. A class of therapeutics named "secretase inhibitors" can inhibit the cutting action of secretases. An example of these drugs in phase III clinical trials is LY-450139, a $\gamma$-secretase inhibitor (Table 1). It has proved to reduce beta-amyloid concentration of the CNS in a dose- 
dependent way [106]. Similarly, a new BACE inhibitor NB-360 demonstrated greater pharmacological efficacy and strong decline in amyloid- $\beta$ level and neuro-inflammation in APP transgenic mice [107].

Another, new class of drugs that that reduces $\gamma$-secretase production is $\mathrm{N}-[\mathrm{N}-(3,5-$ difluorophenacetyl)-L-alanyl]-S-phenyl glycine ester. This compound when injected into mice transgenic for human $\mathrm{APPv} 717 \mathrm{~F}$, it decreases brain levels of $\mathrm{A} \beta$ in a dose-dependent way within 3 hour [108]. Similarly, certain NSAID analogues favorably prevent the formation of Abeta (42) over Abeta (40) and do not disturb Notch processing [109] (Table 1).

Enhancing the beta-amyloid removal from the brain is another way that restores the normal levels of $\mathrm{A} \beta$. This methodology involves mobilization of immune system for creating antibodies, which attack beta-amyloid. Similarly, administration of laboratory-made antibodies to betaamyloid; and natural products with anti-amyloid actions also re-establish normal levels of A $\beta$.

\section{Inhibition of Dominant negative mutations-}

Dominant negative mutations results in toxic misfolding of proinsulin of pancreatic $\beta$-cells thereby leading to diabetes mellitus $[46,47]$. Recently, oral sulfonylurea drugs (Table 1) were reported to treat $\mathrm{HCNJ} 11$ or $\mathrm{ABCC} 8$ mutations, thus obviating the requirement for multiple insulin injections and intensive blood glucose monitoring while improving glycemic control and hopefully preventing or delaying long-standing complications [110-112]. 
Small molecule inhibitors, such as Nutlins have undergone clinical trials for testing drug efficacy against cancers diseases. These compounds prevented MDM2 from binding to and stimulating WT p53 degradation thereby raising the likelihood of forming WT, functional tetramers [113]. Since p53 is involved in various forms of cancer, different compounds that restored the function of mutant p53 have been synthesized. The mechanism by which most of these compounds exert their actions is currently not known; however for one compound, pk7088, the mechanism is well understood [114]. This compound interacts with and stabilizes p53 mutant, Y220C, restores normal functions similar to that of WT protein [114].

\section{Inhibition of Post-translational modifications}

Post-translational alterations of proteins such as glycation, sulfation, and phosphorylation promote misfolding, oligomerization and fibril formation. Hence, inhibition of these posttranslational modifications could potentially control the course of protein misfolding diseases.

\section{Inhibiton of glycation}

Recently, it has been demonstrated that glycation aggravated neurotoxicity of $\mathrm{A} \beta$ with upregulation of receptor for AGE (RAGE) and activation of glycogen synthase kinase-3 (GSK3)[27]. Glycation was inhibited by concurrent application of RAGE antibody or GSK-3 inhibitor, which cured the neuronal damages exacerbated by glycated A $\beta$. Similarly, A $\beta$ is also glycated with age-dependent elevation of AGEs in $\mathrm{Tg} 2576$ mice that bring about cognitive deficit in mice. The A $\beta$-AGE formation was blocked by subcutaneous infusion of aminoguanidine for 3 months. The result showed that early cognitive deficit in mice was significantly reversed [27]. 
Tenilsetam (CAS 997: (+/-)-3-(2-thienyl)-2-piperazinone), a cognition-enhancing drug has been successfully used for the treatment of patients suffering from Alzheimer's disease; it prevents protein crosslinking by AGEs in vitro [115]. The mechanism of Tenilsetam action involves covalent attachment to glycated proteins, thus blocks the reactive sites for further polymerization reactions.

Similarly, plant derived poly-phenols can also provide therapeutic alternatives to hinder the development of AGEs and RAGE-mediated neuro-inflammatory diseases, including Alzheimer's disease [116]. For example, curcumin and resveratrol possess the potential to inhibit AD due to their anti-amyloidogenic, anti-oxidative and anti-inflammatory properties [117]. Furthermore, naturally occurring compounds such as (-) epigallocatechingallate (EGCG) may as well exhibit protective effects against AGE-induced injury of neuronal cells via its antioxidative characteristics, and by inhibiting AGE and RAGE mediated pathways, proposing a valuable role of tea catechin against neurodegenerative diseases[118].

Carnosine a natural dipeptide that has been discovered at elevated levels in brain tissue and the innervated muscle of humans. It has strong antioxidant, metal chelating and antiglycating properties. Carnosine protects neurotoxicity caused by glycated $\quad \beta$-amyloid peptide (A $\beta 25-35)$ to rat brain vascular endothelial cells (RBE4 cell). The homologs of carnosine such as $\beta$-alanine and homocarnosine can also act as therapeutic agents but these drugs are not as effective as carnosine. Thus, it is suggested that carnosine serves as an antiglycating and antioxidant agent that protect RBE4 cells from Alzheimer's disease [119]. 


\section{Inhibiton of phosphorylation}

Tau protein in Alzheimer's disease becomes hyperphosporylated that may add to neuronal degeneration. However, the involved protein kinases are still unknown. Recently, lithium (a glycogen synthase kinase-3 inhibitor) was found to produce tau dephosphorylation at the recognized sites by antibodies of Tau-1 and PHF-1 both in cultured neurons and in vivo in rat brain. Lithium also inhibits the Alzheimer's disease-like proline-directed hyperphosphorylation of tau protein. Thus, lithium could be used to block tau hyperphosphorylation in AD [120]. Similarly, substituted propanone also inhibits the development of abnormally phosphorylated paired helical filament epitope[121]. Chiron company has manufactured purine derivatives which inhibit GSK-3 activity [122].

The bisindolylmaleimides GF 109203x and Ro 31-8220 are shown to be potent inhibitors of GSK-3[123]. Recently, Smithklien Beecham Company has synthesized novel aminoarylmaleimide derivatives which potently inhibited GSK-3 activity and is therefore useful for the treatment of $\mathrm{AD}$, depression, cancer and non-insulin dependent diabetes [124].

Similarly, indenopyrrolocarbazole derivative is an effective modulator of multiple classes of protein kinase. This compound showed neuroprotective effect in three different animal models of motor neuron degeneration [125]. 
Simple heterocyclic compound such as hydroxyflavones or pyrimidones are observed to be GSK-3 inhibitor [126,127].Therefore, compound which inhibits GSK-3 action may demolish $\mathrm{A} \beta$-amyloid protein neurotoxicity and the development of paired helical filaments.

Further, ligands of the small molecule p75NTR decrease pathological phosphorylation and misfolding of tau, inflammatory alterations, cholinergic degeneration, and cognitive deficits in A $\beta P$ (L/S) transgenic mice [128].

\section{Inhibiton of sulfation}

Glycopolymers carrying sulfated saccharides were reported to block the formation of amyloid fibrils. Circular dichroism spectral studies demonstrated the dependence of the amyloid $\beta$ peptides conformation on glycopolymer additives. These additives reduced beta-sheet contents. This was established by neutralization activity conducted by in vitro examination in HeLa cells. Both sulfate group and sugar moiety were observed to be important for the inhibition [129].

Similar studies on the sulfated glycans effect on PrP metabolism in scrapie-infected neuroblastoma cells were performed [130]. The results showed that pentosan polysulfate, like amyloid-binding dye Congo red, prevented the accumulation of PrP-res in the cells with no obvious effects on normal isoform metabolism. The inhibition prevented new PrP-res accumulation instead of destabilization of pre-existing PrP-res. Further, PrP-res accumulation remained declined in the cultures even after removing the inhibitors. The activities of other sulfated glycans in vitro show that PS, lambda-carrageenan, and dextran sulfate 500 being highly more potent as blockers of PrP-res accumulation than heparan or chondroitin sulfate. Since, the 
PrP-res amyloid is identified to encompass endogenous sulfated glycosaminoglycans, in this scenario these compounds may compete for blocking the interaction between $\operatorname{PrP}$ and endogenous glycosaminoglycans, thus exert potent anti-PrP-res activity in neuron-derived cells infected with scrapie thereby preventing amyloid formation. This report also demostrated that the density of sulfation and molecular size are key factors that influence anti-PrP-res activity of sulfated glycans [130].

\section{Inhibition of improper degradation}

Association with multiple chaperones and co-chaperones is a requirement of the CFTR maturation and degradation. Disrupting the function of these chaperone systems may permit mutant CFTR to escape degradation. After knocking-down AHA1, a co-chaperone that together with HSP90 changes the CFTR maturation, CFTR $\triangle \mathrm{F} 58$ not only becomes more stabilized but partly functional [131]. AHA1 is not the only protein that binds chaperones and mediates folding of CFTR. CHIP, a co-chaperone of HSP70, helps in the ubiquitylation and later degrade mutant CFTR [132]; therefore, blockage of the CHIP function may as well permit more CFTR to mature and function. Such studies propose that blocking the chaperone systems can be pharmacologically helpful to people with this mutation

\section{Inhibition of improper localization}

Mutation in alpha-1-antitrypsin in lungs results in loss of function and their accumulation in liver results in gain of toxic function; which can lead to lungs and liver diseases, respectively. The lungs diseases can be controlled by enzyme replacement therapy [133]. However, liver accumulation is harder to control. However, some progress has been achieved in this direction. 
Since aggregates accumulated in liver could be cleared by macroautophagy. Therefore, medications that induce autophagy such as rapamycin and carbamazepine improved $\alpha-1$ antitrypsin induced hepatic toxicity [134]. Alternatively, the mutant $\alpha$-1-antitrypsin aggregates can be directly inhibited by drugs $[135,136]$.

\section{Inhibition of amyloid accumulation}

Because amyloid and other pre-amyloid conformers accumulate in several diseases and share common structural features with fibril formation, intensive research has focused on creating therapeutics that generally target amyloid folds, contrary to targeting specific proteins. Indeed, oligomer-specific antibody that prevents the toxicity of several types of oligomers or recognize both amyloid fibrils and toxic oligomers, in vitro have been recently developed $[137,138]$. Recently, tau monoclonal antibody was generated based on humanized yeast models. The results showed it had impact on tau oligomerization which is indicative that these antibodies hold great promise in diagnostic of AD [139].

Most recently, it was shown that nanobodies from different origins(immune, non-immune or synthetic libraries) could inhibit individual species formed on the pathway of fibril formation[140]. Their binding to specific targets can block fibril formation at various stages ranging from first step (i.e. native state stabilization thereby preventing the formation of amyloidogenic intermediate) to the self-association of protofibrils [140].Thus, these nanobodies in future may prove valuable therapeutic agent in completely curing neurodegenerative diseases. Similarly, Graphene oxide (GO) was reported to be an efficient modulator that may significantly control the amyloidosis of $\mathrm{A} \beta$ [141]. Further, an optimum combination of peony root and ginger 
strongly prevents amyloid- $\beta$ accumulation and amyloid- $\beta$-mediated pathology in A $\beta \mathrm{PP} / \mathrm{PS} 1$ double-transgenic mice [142]. Now research work is focused on emerging antibodies that distinguish both conformation and sequence, thus possibly allowing for more specific therapeutics for treating neurodegenerative diseases [143]. Similarly, many small molecules have been identified that can prevent aggregate formation [144] or enhance their degradation [145].

\section{Inhibition of Oxidative stress}

Antioxidants are exogenous or endogenous compounds that prevent oxidative stress (OS). They neutralize reactive oxygen species (ROS) and other kinds of free radicals that results from oxidative stress and thus are powerful therapeutic agents. Natural antioxidants e.g. flavonoids and phenolic compounds, lipoic acid (thioctic acid), ubiquinone and idebenone, $\beta$-carotene and vitamin C are important therapeutic agents that keep all our vital organs free from OS [102].

\section{Inhibition of upstream of oxidative stress}

There are several reports that indicate neurodegenerations can be ameliorated by dietary intake or supplementary administration of natural antioxidants. Dietary intake containing a variety of antioxidants including vitamin supplements plays an essential role in preventing different neurological disorders [146].

These natural antioxidants prevented oxidation of proteins, lipid peroxidations and production of ROS thus act as an upstream of oxidative stress. An important upstream therapeutic strategy for inhibiting oxidative stress is vaccination against toxic fibril which is common to all different types of neuronal disorders. For instance, amyloid- $\beta$ vaccination prevents formation of plaque 
and neuron inflammation that occurs in $\mathrm{AD}$ [147]. This finding could provide platform for other types of neurological disorders caused by oxidative disorder.

\section{Inhibition of downstream of oxidative stress}

ROS are generated by several pathways that results in a number of side reactions, which interact with neuronal cells in a direct or indirect way. This post-oxidative stress may be prevented by natural and synthetic antioxidants. Among all antioxidants, Ginkgo biloba (EGb 761), a Chinese herb proves an excellent antioxidant that ameliorates $\beta$-amyloid induced toxicity after plaque formation [148]. In mild $\mathrm{AD}$ patients, this drug EGb 761 improves cognitive decline and neuronal function but in severe $\mathrm{AD}$, neuroprotective role of EGb 761 is reduced. Since inflammatory reactions are common to all types of neuronal disorders. Therefore, NSAIDS are most effective downstream therapeutics that reduces inflammatory infiltration of macrophages. These drugs act via antioxidative mechanism, which reduces inflammatory reactions resulted from oxidative stress [149]. Similarly CPI-1189, a nitrone related compound down-regulated the pro-inflammatory cytokine cascade of genes in primary glial cells. The nitron and related compounds are under phase III clinical trial [150]. A new methodology involves stimulation of in vivo proteins and growth factors such as brain derived neurotrophic factors, responsible for boosting memory and cognitive function in OS [151]. This methodology could particularly prove useful for treating deteriorating neurons.

Similarly, a chemical substance such as hormone estrogen (estradiol) resembles most to vitamin $\mathrm{E}$ in chemical structure. It contains a phenolic free radical scavenging site and thus yielding the antioxidant activity [152]. 


\section{Conclusions}

Protein misfolding is a process by which protein molecule acquires wrong tertiary structure thus induces protein misfolding diseases. Protein misfolding leading to diseases conditions occur by several mechanisms as discussed above. Treatment of misfolding maladies is utmost important. Several novel therapeutic strategies were discussed here. These therapeutic interventions partly reversed or prevented the pathological state. Most recently nanobodies from different origins (immune, non-immune or synthetic libraries) have been discovered. These nanobodies could target individual species formed on the pathway of fibril formation [140], thus possibly may allow for more complete treatment of neurodegenerative diseases. Now research work is focused on emerging antibodies that distinguish both conformation and sequence, thus possibly allowing more specific therapeutics for neurodegenerative diseases [143].

\section{Acknowledgements}

Authors acknowledge the facilities of Distributed Information Sub-centre, Interdisciplinary Biotechnology Unit, A.M.U., Aligarh, 202002, India.M.K. Siddiqi is highly thankful to Department of Biotechnology (DBT), New Delhi, for providing fellowship in the form of junior research fellowship (JRF).The authors would like to extend their sincere appreciation to the Deanship of Scientific Research at King Saud University for its funding this Research Group No. 


\section{References}

1. Uversky, V.N. (2014). The triple power of $\mathrm{D}^{3}$ : protein intrinsic disorder in degenerative diseases. Frontiesin Biosciences, 19, 181-258.

2. Goldberger, R.F., Epstein, C.J., \&Anfinsen, C.B.(1963). Acceleration of reactivation of reduced bovine pancreatic ribonuclease by a microsomal system from rat liver. Journal ofBiological Chemistry, 238, 628-635.

3. London, J., Skrzynia, C.,\& Goldberg, M.E.(1974).Renaturation of Escherichia coli tryptophanase after exposure to $8 \mathrm{M}$ urea.Evidence for the existence of nucleation centers.Euopean Journal of Biochemistry, 47, 409-415.

4. Speed, M.A., Wang, D.I.C., \& King, J. (1995).Multimeric intermediates in the pathway to the aggregated inclusion body state for P22 tailspike polypeptide chains. Protein Science, 4, 900-908.

5. Mitraki, A., \&King, J. (1989).Protein Folding Intermediates and Inclusion Body Formation.Nature Biotechnology,7,690-697.

6. Wetzel, R.(1996).For protein misassembly, it's the "I" decade.Cell, 86, 699-702.

7. Serpell, L.C., Sunde, M., Benson, M.D., et al.(2000). The protofilament substructure of amyloid fibrils.Journalof Molecular Biology, 300,1033-1039.

8. Bauer, H.H., Aebi, U., Häner, M., et al. (1995).Architecture and polymorphism of fibrillarsupramolecular assemblies produced by in vitro aggregation of human calcitonin.Journal of Structural Biology, 115, 1-15.

9. Saiki, M., Honda, S., Kawasaki, K., et al. (2005). Higher-order molecular packing in amyloid-like fibrils constructed with linear arrangements of hydrophobic and hydrogenbonding side-chains. Journal of Molecular Biology, 348, 983-998.

10. Salahuddin, P., Fatima, M.T., Abdelhameed, A.S, et al. (2016).Structure of amyloid oligomers and their mechanisms of toxicities: Targeting amyloid oligomers using novel therapeutic approaches.European. Journal of Medicinal Chemistry, 114,41-58

11. Forloni, G., Artuso, V., La Vitola, P.1., et al.(2016).Oligomeropathies and pathogenesis of Alzheimer and Parkinson's diseases. Movement Disorders.2016 Mar 31. doi: 10.1002/mds.26624. [Epub ahead of print]

12. Schwalbe, M., Ozenne, V., \& Bibow, S.(2014).Predictive atomic resolution descriptions of intrinsically disordered hTau 40 and $\alpha$-synuclein in solution from NMR and small angle scattering.Structure, 22, 238-249.

13. Ahuja, P., Cantrelle, F.X.,\& Huvent, I. (2016).Proline Conformation in a Functional Tau Fragment.Journal of Molecular Biology, 428,79-91.

14. Kondo, A., Shahpasand, K., Mannix, R., et al.(2015).Antibody against early driver of neurodegeneration cis P-tau blocks brain injury and tauopathy.Nature. 523,431-436.

15. Mohan, R.1.,\& John, A.1.(2015).Microtubule-associated proteins as direct crosslinkers of actin filaments and microtubules. International Union of Biochemistry and Molecular Biology Life. 67, 395-403.

16. Kadavath, H., Hofele, R.V., Biernat, J., et al.(2015).Tau stabilizes microtubules by binding at the interface between tubulin heterodimers. Proceeding National Academy of Science U S A. 112, 7501-7506.

17. Kadavath, H., Jaremko, M., Jaremko, Ł., et al. (2015). Folding of the Tau Protein on Microtubules. Angewandte Chemie International Edition in English, 54, 10347-10351. 
18. Huang, A, \&Stultz, C.M.(2008).The effect of a DeltaK280 mutation on the unfolded state of a microtubule-binding repeat in Tau.PLoS Computational Biology, 4, e1000155.

19. Igaev, M., Janning, D., \&Sündermann, F.(2014).A refined reaction diffusion model of taumicrotubule dynamics and its application in FDAP analysis. Biophysical Journal,107, 2567 -2578 .

20. Støy, J., Edghill, E.L., Flanagan, S.E., et al.(2007).Insulin gene mutations as a cause of permanent neonatal diabetes.Proceeding National Academy of Science U S A, 104(38), $15040-15044$.

21. Colombo, C., Porzio, O., Liu, M., et al.(2008).Seven mutations in the human insulin gene linked to permanent neonatal/infancy-onset diabetes mellitus. Journal of Clinical Investigation, 118(6),2148-2156.

22. Edghill, E.L., Flanagan, S.E., Patch, A.M., et al. (2008). Insulin mutation screening in 1,044 patients with diabetes: mutations in the INS gene are a common cause of neonatal diabetes but a rare cause of diabetes diagnosed in childhood or adulthood. Diabetes, 57(4), 1034-1042.

23. Molven, A., Ringdal, M., Nordbø, A.M., et al. (2008). Mutations in the insulin gene can cause MODY and autoantibody-negative type 1 diabetes. Diabetes, 57(4),1131-1135.

24 Park, S.Y., Ye, H., Steiner, D.F., et al.(2010).Mutant proinsulin proteins associated with neonatal diabetes are retained in the endoplasmic reticulum and not efficiently secreted. Biochemistry Biophysics Research Communication, 391(3),1449-1454.

25. Liu, M., Haataja, L., Wright, J., etal. (2010). Mutant INSgene induced diabetes of youth: proinsulin cysteine residues imposedominant-negative inhibition on wild-type proinsulin transport.PLoS One. , 5(10), e13333.

26 Salahuddin, P., Rabbani, G., \&Khan, R.H.(2014).The role of advanced glycation end products in various types of neurodegenerative disease: A therapeutic approach. Cellular Moecular Biology Letters. 19, 407-437.

27. Li, X.H., Du, L.L., Cheng, X.S., et al. (2013). Glycation exacerbates the neuronal toxicity of $\beta$-amyloid. Cell Death and Disease, 4, e673.

28. Kumar, S., \&Walter, J. (2011).Phosphorylation of amyloid beta (A $\beta$ ) peptides - a trigger for formation of toxic aggregates in Alzheimer's disease.Aging (Albany NY), 3(8), 803-812.

29. Kumar, S., Rezaei-Ghaleh N., Terwel, D., et al. (2011). Extracellular phosphorylation of the amyloid beta-peptide promotes formation of toxic aggregates during the pathogenesis of Alzheimer's disease. European Molecular Biology Organization Journal,30, 2255-2265.

30. Mi, K., \& Johnson, G.V. (2006). The role of tau phosphorylation in the pathogenesis of Alzheimer's disease. Current Alzheimer Research, 3,449-463.

31. Ariga, T., Miyatake, T., \&Yu, R.K.(2010).Role of proteoglycans and glycosaminoglycans in the pathogenesis of Alzheimer's disease and related disorders: amyloidogenesis and therapeutic strategies--a review. Journal of Neuroscience Research, 88(11),2303-2315.

32. Valastyan, J.S., \&Lindquist, S.(2014).Mechanisms of protein-folding diseases at a glance. Disease Models and Mechanism, 7(1),9-14.

33. Qu, B. H., Strickland E. H., \&Thomas P. J. (1997). Localization and suppression of a kinetic defect in cystic fibrosis transmembrane conductance regulator folding. Journal of Biological Chemistry, 272, 15739-15744.

34. Lomas, D. A., Evans D. L., Finch J. T.,\& Carrell R. W. (1992). The mechanism of Z alpha 1-antitrypsin accumulation in the liver. Nature, 357, 605-607. 
35. Lee, V.M., Goedert, M., \& Trojanowski, J.Q.(2001).Neurodegenerative tauopathies. Annual Review of Neuroscience, 24,1121-1159.

36. Fraser, P.E., Nguyen, J.T., Surewicz, W.K., et al.(1991).pH-dependent structural transitions of Alzheimer amyloid peptides. Biophysical Journal, 60(5), 1190-1201.

37. Su, Y., \& Chang, P.T.(2001).Acidic $\mathrm{pH}$ promotes the formation of toxic fibrils from betaamyloid peptide. Brain Research, 893(1-2),287-291.

38. Kř́íz, Z., Klusák, J., Krištofíková, Z., et al.(2013).How ionic strength affects the conformational behavior of human and rat beta amyloids--a computational study.PLoS One,8(5), e62914.

39. de Azevedo, W.F. Jr.(2011).Molecular dynamics simulations of protein targets identified in Mycobacterium tuberculosis.Current Medicinal Chemistry. 18,1353-1366.

40. Bossis, F., \&Palese, L.L.(2013).Amyloid beta(1-42) in aqueous environments: effects of ionic strength and E22Q (Dutch) mutation.Biochimica Biophysica Acta,1834, 2486-2493.

41 Lin, S.Y., Chu, H.L., \&Wei, Y.S.(2003).Secondary conformations and temperature effect on structural transformation of amyloid beta (1-28), (1-40) and (1-42) peptides.Journal of Biomolecular Structure and Dynamics, 20(4), 595-601.

42. van Gool, W.A., Schenk, D.B.,\& Bolhuis, P.A.(1994).Concentrations of amyloid-beta protein in cerebrospinal fluid increase with age in patients free from neurodegenerative disease.Neuroscience Letters, 172(1-2),122-124.

43. Stoy, J., Edghill, E.L., Flanagan, S.E., et al.(2007).Insulin gene mutations as a cause of permanent neonatal diabetes. Proceeding Natlional Academy of Science U S A,104,1504015044.

44. Colombo, C., Porzio, O., Liu, M., et al.(2008). Seven mutations in the human insulin gene linked to permanent neonatal/infancy-onset diabetes mellitus. Journal of Clinical Investigation, 118,2148-2156.

45. Edghill, E.L., Flanagan, S.E., Patch, A.M., et al. (2008). Insulin mutation screening in 1044 patients with diabetes: mutations in the INS gene are a common cause of neonatal diabetes but a rare cause of diabetes diagnosed in childhood or adulthood. Diabetes ,57, 1034-1042.

46. Park, S.Y., Ye, H., Steiner, D.F., et al. (2010). Mutant proinsulin proteins associated with neonatal diabetes are retained in the endoplasmic reticulum and not efficiently secreted. Biochemical Biophysical Research Communication, 391, 1449-1454.

47. Liu, M., Haataja, L., Wright, J., et al. (2010). Mutant INS-gene induced diabetes of youth: proinsulin cysteine residues impose dominant-negative inhibition on nonmutant proinsulin transport. PLos-One. 5(10),e13333.

48. Meur, G., Simon, A., Harun, N., et al. (2010). Insulin gene mutations resulting in early-onset diabetes: marked differences in clinical presentation, metabolic status, and pathogenic effect through endoplasmic reticulum retention. Diabetes ,59, 653-661.

49. Yoshioka, M., Kayo, T., Ikeda, T. et al. (1997). A novel locus, Mody4, distal to D7Mit189 on chromosome 7 determines early-onset NIDDM in nonobese C57BL/6 (Akita) mutant mice. Diabetes, 46,887-894.

50. Wang, J., Takeuchi, T., Tanaka, S., et al. (1999). A mutation in the insulin 2 gene induces diabetes with severe pancreatic $\beta$-cell dysfunction in the Mody mouse. Journal of Clinical Investigation, 103,27-37.

51. Oyadomari, S., Koizumi, A., Takeda, K., et al.(2002). Targeted disruption of the Chop gene delays endoplasmic reticulum stress-mediated diabetes. Journal of Clinical Investigation, $109,525-532$. 
52. Yoshinaga, T., Nakatome, K., Nozaki,J., et al. (2005). Proinsulin lacking the A7-B7 disulfide bond, Ins2Akita, tends to aggregate due to the exposed hydrophobic surface. Biological Chemistry, 386, 1077-1085.

53. Hong, B., van den Heuvel, A.P., Prabhu, V.V et al.(2014).Targeting tumor suppressor p53 for cancer therapy: strategies, challenges and opportunities.Current DrugTargets, 15, 80-89.

54. Dean, J.L., \& Knudsen, K.E.(2013). The role of tumor suppressor dysregulation in prostate cancer progression.Current Drug Targets, 14, 460-471.

55. Vogelstein, B., Lane, D., \& Levine, A. J. (2000).Surfing the p53 network. Nature,408, 307310.

56. Vousden, K. H.,\& Lane, D. P.(2007). p53 in health and disease.Nature Reviews Molecular Cell Biology, 8,275-283.

57. Brown, C. J., Lain, S., Verma, C. S., et al. (2009). Awakening guardian angels: drugging the p53 pathway. Nature Review Cancer, 9,862-873.

58. Schon, O., Friedler, A., Bycroft,M., et al.(2002).Molecular mechanism of the interaction between MDM2 and p53. Journal of Molecular Biology, 323,491-501.

59. Kussie, P. H., Gorina, S., Marechal, V., et al. (1996). Structure of the MDM2 oncoprotein bound to the p53 tumor suppressor transactivation domain. Science, 274,948-953.

60. Pennisi, E.(1996).Filling in the blanks in the p53 protein structure. Science, 274,921-922.

61. Joerger, A. C., \&Fersht A. R. (2008).Structural biology of the tumor suppressor p53. Annual Review Biochemistry, 77,557-582.

62. Silva, J.L., De Moura Gallo, C.V., \& Costa, D.C. (2014). Rangel, L.P.Prion-like aggregation of mutant p53 in cancer.Trends. Biochem. Sci. 39, 260-267.

63. Abedini, A., Gupta, R., Marek, P., et al.( 2010). In: Protein Misfolding Diseases: Current and Emerging Principles and Therapies. Ramirez-Alvarado M, Kelly JW, Dobson CM, Eds) John Wiley and Sons, Inc pp. 131.

64. Nilsson, M.R. (2005).In: Amyloid Proteins. the Beta Sheet Conformation and Disease. Sipe JD, Ed). Weinheim: WILEY-VCH Verlag GmbH \& Co. KGaA; pp 81.

65. Walter, J.,\& Haass, C.(2000). Posttranslational modifications of amyloid precursor protein :ectodomain phosphorylation and sulfation. Methods in Molecular Medicine, 32,149-168.

66. Georgopoulou, N., McLaughlin, M., McFarlane, I., et al. (2001). The role of posttranslational modification in beta-amyloid precursor protein processing. Biochemical Society Symposium, 23-36.

67 Haass, C., \& Selkoe, D.J. (2007). Soluble protein oligomers in neurodegeneration: lessons from the Alzheimer's amyloid beta-peptide. Nature Review Molecular Cell Biology, 8,101112 .

68 Tay, W.M., Bryant, J.G., Martin,P.K.,et al. (2012).A mass spectrometric approach for characterization of amyloid-beta aggregates and identification of their post-translational modifications. Biochemistry, 51,3759-3766.

69. Miyata, T., Oda, O., Inagi, R., et al.(1993). b2-Microglobulin modified with advanced glycation end products is a major component of hemodialysis-associated amyloidosis. Journal of Clinical Investigation, 92, 1243-1252.

70. Kikuchi, S., Ogata, A., Shinpo, K., et al. (2000). Detection of an amadori product, 1-hexitollysine, in the anterior horn of the amyotrophic lateral sclerosis and spinobulbar muscular atrophy spinal cord: evidence for early involvement of glycation in motoneuron diseases. Acta Neuropathology, 99, 63-66. 
71. Munch, G., Luth, H. J., Wong, A., et al. (2000). Crosslinking of alpha-synuclein by advanced glycationendproducts-an early pathophysiological step in lewy body formation? Journal of Chemistry Neuroanatomy, 20, 253-257.

72. Dukic-Stefanovic, S., Schinzel, R., Riederer, P., et al. (2001). AGES in brain ageing: AGEinhibitors as neuroprotective and anti-dementia drugs? Biogerontology, 2, 19-34.

73. Shults, C. W. (2006). Lewy bodies. Proceeding National Academy of Science USA,103, 1661-1668.

74. Furber, J. D. (2010). Repairing extracellular aging and glycation, in The Future of Aging: Pathways to Human Life Extension, Fahy G. M., Ed) Springer, Norco, CA, pp587-622.

-75.Iannuzzi, C., Irace, G., \& Sirangelo, I.(2014).Differential effects of glycation on protein aggregation and amyloid formation. Frontiersin Molecular Biosciences, 1, 9.

76. Vicente, M. H., \& Outeiro T. F. (2010). The sour side of neurodegenerative disorders: the effects of protein glycation. Journal of Pathology, 221, 13-25.

77. Lee, D., Park, C. W., Paik, S. R.,et al. (2009). The modification of alpha-synuclein by dicarbonyl compounds inhibits its fibril-forming process. Biochimica Biophysica Acta, 1794, 421-430.

78. Chen, L., Wei, Y., Wang,X.,et al. (2010). Ribosylation rapidly induces alpha-synuclein to form highly cytotoxic molten globules of advanced glycation end products. PLoS ONE, 5, e9052.

79. Kumar, S., Wirths, O., \&Stüber, K.(2016). Phosphorylation of the amyloid $\beta$-peptide at Ser26 stabilizes oligomeric assembly and increases neurotoxicity.Acta Neuropathol,131, 525-537.

80. Chun, W., \& Johnson, G.V.(2007).The role of tau phosphorylation and cleavage in neuronal cell death. Frontiers in Biosciences, 12, 733-756.

81. Iannuzzi, C., Irace, G., \& Sirangelo, I.(2015).The effect of glycosaminoglycans (GAGs) on amyloid aggregation and toxicity. Molecules, 20(2), 2510-2528.

82. Ellett, L.J., Coleman, B.M., Shambrook, M.C., et al.(2015). Glycosaminoglycan sulfation determines the biochemical properties of prion protein aggregates. Glycobiology, 25(7), 745-755.

83. Qu, B. H., Strickland, E. H., \&Thomas, P. J. (1997). Localization and suppression of a kinetic defect in cystic fibrosis transmembrane conductance regulator folding. Journal of Biological Chemistry, 272, 15739-15744.

84. Futerman, A.H., \&van Meer, G.(2004). The cell biology of lysosomal storage disorders. Nature Review Molecular Cell Biology,5,554-565.

85. Cox, T.M., \& Cachón-González, M.B.(2012). The cellular pathology of lysosomal diseases. Journal of Pathology, 226, 241-254.

86. Caughey, B., \& Lansbury, P. T. (2003). Protofibrils, pores, fibrils, and neurodegeneration: separating the responsible protein aggregates from the innocent bystanders. Annual Review of Neuroscience, 26, 267-298.

87. Chiti, F., \& Dobson, C. M. (2006). Protein misfolding, functional amyloid, and human disease. Annual Review of Biochemistry, 75, 333-366.

88. Treusch, S., Cyr, D. M., \& Lindquist, S. (2009). Amyloid deposits: protection against toxic protein species? Cell Cycle, 8, 1668-1674.

89. Wolfe, K.J., \& Cyr, D.M. (2011). Amyloid in neurodegenerative diseases: friend or foe? Seminars in Cell Developmental Biology, 22, 476-481. 
90. Luk, K. C., Kehm, V., Carroll, J., et al. (2012). Pathological $\alpha$-synuclein transmission initiates Parkinson-like neurodegeneration in nontransgenic mice. Science, 338,949-953.

91. Nath, S., Agholme, L., Kurudenkandy, F.R., et al. (2012).Spreading of neurodegenerative pathology via neuron-to-neuron transmission of beta-amyloid. Journal of Neuroscience, $32,8767-8777$.

92. Iba, M., Guo, J. L., McBride, J.D., et al. (2013).Synthetic tau fibrils mediate transmission of neurofibrillary tangles in a transgenic mouse model of Alzheimer's like tauopathy. Journal of Neurosience, 33, 1024-1037.

93. Lindholm, D.,Wootz, H. \& Korhonen,L.(2006). ER stress and neurodegenerative diseases. Cell Death Differeniation, 13,385-392.

94. Dias-Santagata,D., Fulga, T.A., Duttaroy,A., et al.(2007). Oxidative stress mediates tauinduced neurodegeneration in Drosophilia.Journal of Clinical Investigation, 117,236-245.

95. Shimura,H.,Hattori,N.,Kubo,S., et al.(2000).Familial Parkinson disease gene product, parkin, is a ubiquitin-protienligase.Nature Genetics, 25,302-305.

96. Imai, Y.,Soda,M., \& Takahashi, R.(2000).Parkin suppresses unfolded protein stress-induced cell death through its E3 Ubiquitin-protein ligase activity.Journal of Biological Chemistry, 275,35661-35664.

97. Holtz, W.A.,\& O’Malley, K.L. (2003).Parkinsonian mimetics induce aspects of unfolded protein response in death of dopaminergic neurons.Journal of Biological Chemistry,278, 19367-19377.

98. Conn, K. J., Gao,W., McKee, A., et al.(2004). Identification of protein disulfide isomerase family member PDIp in experimental Parkinson's disease and Lewy body pathology. Brain Research, 1022,164-172.

99. Teplow, D.B. (2006).Preparation of amyloid beta-protein for structural and functional studies.Methods in Enzymology, 413, 20-33.

100.Sinigaglia-Coimbra, R., Cavalheiro, E.A., \& Coimbra, C.G.(2002).Postischemic hyperthermia induces Alzheimer-like pathology in the rat brain. Acta Neuropathologica, 103,444-452101.

101.Krishnaswamy, S., Verdile, G., Groth, D., et al.(2010). The structure and function of Alzheimer's gamma secretase enzyme complex.Neuromolecular Medicine, 12, 1-12.

102.Lepoivre, M., Flaman, J.M., Bobé, P., et al.(1994).Quenching of the tyrosyl free radical of ribonucleotide reductase by nitric oxide. J. Biol. Chem. 269,21891-21897.

103.Chow, V.W., Mattson, M.P., Wong, P.C., et al. (2009).An overview of APP processing enzymes and products.Neurosci. 29, 12787-12794.

104.Vassar, R, Kovacs, D.M., Yan, R., et al.(2010).The beta-secretase enzyme BACE in health and Alzheimer's disease: regulation, cell biology, function, and therapeutic potential.Journal of Neurochemistry, 112,1045-1053.

105.Ahmed, R.R., Holler, C.J., et al. (2009).BACE1 and BACE2 enzymatic activities in Alzheimer's disease.Critical Review of Clinical Laboratory Science. 46, 282-301. 
106.Bateman, R.J., Siemers, E.R., Mawuenyega, K.G., et al.(2009).A gamma-secretase inhibitor decreases amyloid-beta production in the central nervous system. Annals of Neurology, 66(1), 48-54.

107.Neumann, U., Rueeger, H., Machauer, R., et al.(2015).A novel BACE inhibitor NB-360 shows a superior pharmacological profile and robust reduction of amyloid- $\beta$ and neuroinflammation in APP transgenic mice. Molecular Neurodegeneration, 10, 44.

108.Dovey, H.F., John, V., Anderson, J.P., et al.(2001).Functional gamma-secretase inhibitors reduce beta-amyloid peptide levels in brain. Journal of Neurochemistry, 76(1), 173-181.

109.Evin, G., Sernee, M.F., \&Masters, C.L.(2006).Inhibition of gamma-secretase as a therapeutic intervention for Alzheimer's disease: prospects, limitations and strategies. CNS Drugs, 20(5), 351-372.

110.Ashcroft, F.M.(2010). New uses for old drugs: Neonatal diabetes and sulphonylureas. Cell Metabolism, 11,179-181.

111.Støy, J., Greeley, S.A., Paz, V.P., et al.(2008). Diagnosis and treatment of neonatal diabetes: A United States experience. Pediatrics Diabetes, 9,450-459.

112.Zung, A., Glaser, B., Nimri, R., et al.(2004).Glibenclamide treatment in permanent neonatal diabetes mellitus due to an activating mutation in Kir6.2. Journal of Clinical Endocrinology Metabolism, 89, $5504-5507$.

113.Vassilev, L.T., Vu, B.T., Graves, B., et al.(2004). In vivo activation of the p53 pathway by small-molecule antagonists of MDM2. Science, 303, 844-848.

114.Liu, X., Wilcken, R., Joerger, A.C., et al. (2013). Small molecule induced reactivation of mutant p53 in cancer cells. Nucleic Acids Research, 41, 6034-6044.

115.Münch, G., Taneli, Y., Schraven, E., et al.(1994).The cognition-enhancing drug tenilsetam is an inhibitor of protein crosslinking by advanced glycosylation. Journal of Neural Transission Parkinson's Disease and Dementia Section, 8(3),193-208.

116.Chandler, D., Woldu, A., Rahmadi, A., et al. (2010). Effects of plant-derived polyphenols on TNF-alpha and nitric oxide production induced by advanced glycation end products. Molecular Nutrition and Food Research, 54,141-150.

117.Kim, J., Lee, H. J.,\& Lee, K.W. (2010). Naturally occurring phytochemicals for the prevention of Alzheimer's disease.Journal of Neurochemistry, 112,1415-1430.

118.Weinreb, O., Amit, T., Mandel, S.,et al.(2009).Neuroprotective molecular mechanisms of (-)-epigallocatechin-3-gallate, a reflective outcome of its antioxidant, iron chelating and neuritogenic properties.Genes Nutrition, 4,283-296.

119. Preston, J. E., Hipkiss, A. R., Himsworth, D. T., et al.(1998).Toxic effects of betaamyloid (25-35) on immortalised rat brain endothelial cell: protection by carnosine, homocarnosine and beta-alanine. Neuroscience Letters, 242, 105-108.

120.Muñoz-Montaño, J.R., Moreno, F.J., Avila, J., et al.(1997).Lithium inhibits Alzheimer's disease-like tau protein phosphorylation in neurons. FEBS Letters, 411(2-3), 183-188.

121.Molecular Geriatrics Corp. US Patent US5658909(1997).

122.Chiron Corp.CA Patent WO9816528(1998).

123.Hers, I.,Tavare, J.M., \& Denton, R.M.(1999). The protein kinase c inhibitors bisindolylmale imide I(GF109203x)and IX(Ro31-8220) are potent inhibitors of glycogen synthase kinase-3 activity. FEBS Letters, 460, 433-436.

124.Smith Klien Beecham.PatentWO0021927(2000).

125.Cephalon, Inc.US Patent WO0013015(2000). 
126.Mitsubishi Chemical Corp.European Patent WO0017184(2000).

127.Mitsubishi Chemical Corp.European Patent WO0018758(2000).

128.Nguyen, T.V., Shen, L., Vander Griend, L., et al. (2014).Small molecule p75NTR ligands reduce pathological phosphorylation and misfolding of tau, inflammatory changes, cholinergic degeneration, and cognitive deficits in $\mathrm{A} \beta \mathrm{PP}(\mathrm{L} / \mathrm{S})$ transgenic mice. Journal ofAlzheimer's Disease, 42(2), 459-483.

129.Miura,Y., Yasuda,K., Yamamoto, K., et al.(2007).Inhibition of Alzheimer amyloid aggregation with sulfated glycopolymers.Biomacromolecules, 8(7), 2129-2134.

130.Caughey, B., \&Raymond, G.J.(1993).Sulfated polyanion inhibition of scrapie-associated PrP accumulation in cultured cells.Journal of Virology, 67(2),643-650.

131.Wang, X.D., Venable, J., LaPointe, P., etal.(2006).Hsp90 co chaperone Aha1 downregulation rescues misfolding of CFTR in cystic fibrosis. Cell, 127, 803-815.

132.Meacham, G.C., Patterson, C., Zhang, W., et al.(2001). The Hsc70 co-chaperone CHIP targets immature CFTR for proteasomal degradation. Nature Cell Biology, 3, 100-105.

133.Mohanka, M., Khemasuwan, D., \&Stoller, J. K. (2012). A review of augmentation therapy for alpha-1 antitrypsin deficiency. Expert Opinionon Biological Therapy, 12, 685-700.

134.Hidvegi, T., Schmidt, B. Z., Hale, P., et al.(2005). Accumulation of mutant alpha1antitrypsin $\mathrm{Z}$ in the endoplasmic reticulum activates caspases-4 and -12, NFkappaB, and BAP31 but not the unfolded protein response. Journal of Biological Chemistry, 280, 3900239015.

135.Skinner, R., Chang, W. S., Jin, L., et al. (1998).Implications for function and therapy of a 2.9 A structure of binary-complexedantithrombin. Journal of Molecular Biology, 283,9-1.

136.Phillips, R. L., Saldanha, S. A., Gooptu, B., et al.(2007). Small molecules block the polymerization of $\mathrm{Z}$ alpha1-antitrypsin and increase the clearance of intracellular aggregates. Journal of Medicinal Chemistry, 50, 5357-5363.

137.Kayed, R., Head, E., Thompson, J. L., et al. (2003). Common structure of soluble amyloid oligomers implies common mechanism of pathogenesis.Science, 300, 486-489.

138.Glabe, C. G. (2004). Conformation-dependent antibodies target diseases of protein misfolding. Trends in Biochemical Science, 29, 542-547.

139.Rosseels,J.,Van den Brande, J., \&Violet, M.( 2015).Tau monoclonal antibody generation based on humanized yeast models: impact on Tau oligomerization and diagnostics.Journal of Biological Chemistry, 290,4059-4074.

140.Pain, C., Dumont, J., \& Dumoulin, M.(2015).Camelid single-domain antibody fragments: Uses and prospects to investigate protein misfolding and aggregation, and to treat diseases associated with these phenomena. Biochimie, 111, 82-106.

141.Wang, J., Cao, Y., Li, Q., et al.(2015).Size effect of graphene oxide on modulating amyloid peptide assembly. Chemistry, 21(27), 9632-9637.

142.Lim, S., Choi, J.G., Moon, M., et al.(2015).An Optimized Combination of Ginger and Peony Root Effectively Inhibits Amyloid- $\beta$ Accumulation and Amyloid- $\beta$-Mediated Pathology in A $\beta P P / P S 1$ Double-Transgenic Mice.Journal of Alzheimer's Disease, [Epub ahead of print]

143.Perchiacca, J.M., Ladiwala, A.R., Bhattacharya, M., et al. (2012). Structure-based design of conformation- and sequence-specific antibodies against amyloid $\beta$. Proceeding National Academy of Science USA, 109, 84-89.

144.Ehrnhoefer, D.E., Bieschke, J., Boeddrich, A., et al.(2008). EGCG redirects amyloidogenic polypeptides into unstructured, off-pathway oligomers. Nature Structural and Molecular Biology, 15, 558-566. 
145.Rubinsztein, D.C., Gestwicki, J.E., Murphy, L.O.,et al.(2007).Potential therapeutic applications of autophagy. Nature Review Drug Discovery, 6, 304-312.

146.Peter, P.Z., James, C., Anthon, A. S, et al.(2004). Reduced risk of Alzheimer disease in users of antioxidant vitamin supplements-The Cache County Study. Archives of Neurology, 61,82-88.

147.Janus, C., Pearson, J., McLaurin, J., et al.(2000). A peptide immunization reduces behavioral impairment and plaques in a model of Alzheimer's disease. Nature, 408,979-982.

148.Yao, Z., Drieu,K., \& Papadopoulos, V.(2001). The Ginkgo biloba extract EGb 761 rescues the PC12 neuronal cells from beta-amyloid-induced cell death by inhibiting the formation of beta-amyloid-derived diffusible neurotoxic ligands.Brain Research, 889, 181-190.

149.Floyd, R.A., \& Hensley, K. (2002).Oxidative stress in brain aging.Implications for therapeutics of neurodegenerative diseases. Neurobiol-Aging, 23(5), 795-807.

150. Floyd, R. A.(1997). Protective action of nitrone-based free radical traps against oxidative damage to the central nervous system. Advances in Pharmacology,38, 361-378.

151.Mattson, M.P.(2003). Will caloric restriction and folate protect against AD and PD? Neurology, 60, 690-695.

152.Green, P.S., \& Simpkins, J.W.(2000). Neuroprotective effects of estrogens: potential mechanisms of action. International Journal of Developmental Neuroscience, 18, 347-358. 


\section{Legends to Figure}

Fig.1 Energy landscape scheme of protein folding and aggregation.The landscape scheme shows the different types of aggregates including amorphous aggregates, oligomers, and fibrils.

Fig.2 Proteolytic processing of amyloid precursor protein by different secratases including $\alpha$ secretase, $\beta$-secretase and $\gamma$-secretase.

Fig.3 AGE synthesis, a non-enzymatic condensation reaction occurs between $\alpha$-amino or $\mathrm{N}$ terminal group of a protein, and the carbonyl group of a reducing sugar leading to production of cross-linked AGEs which forms fibril structure culminating into amyloid diseases.

Fig.4 Sulfation or phosphorylation of protein and their aberrant interactions give rise to fibril structure which induces neurotoxicity. 


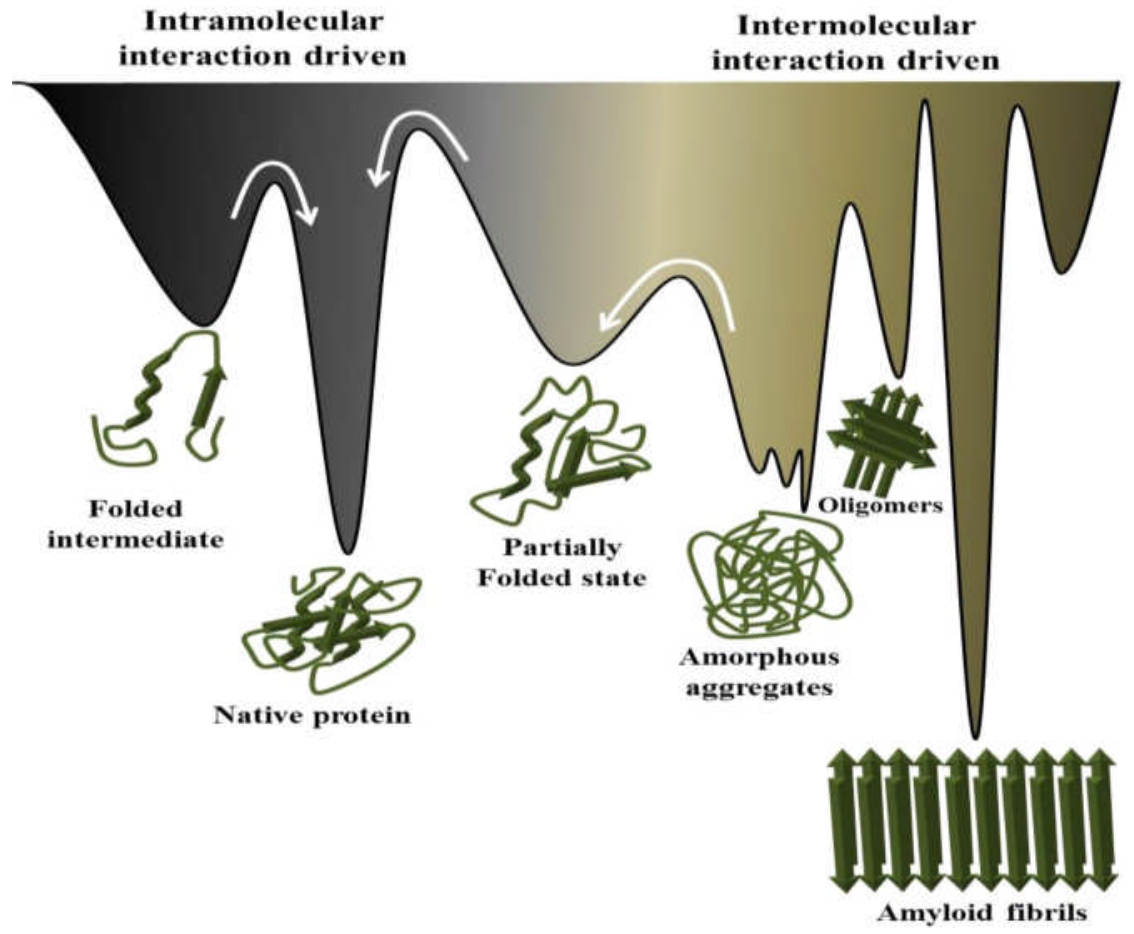

Figure 1 


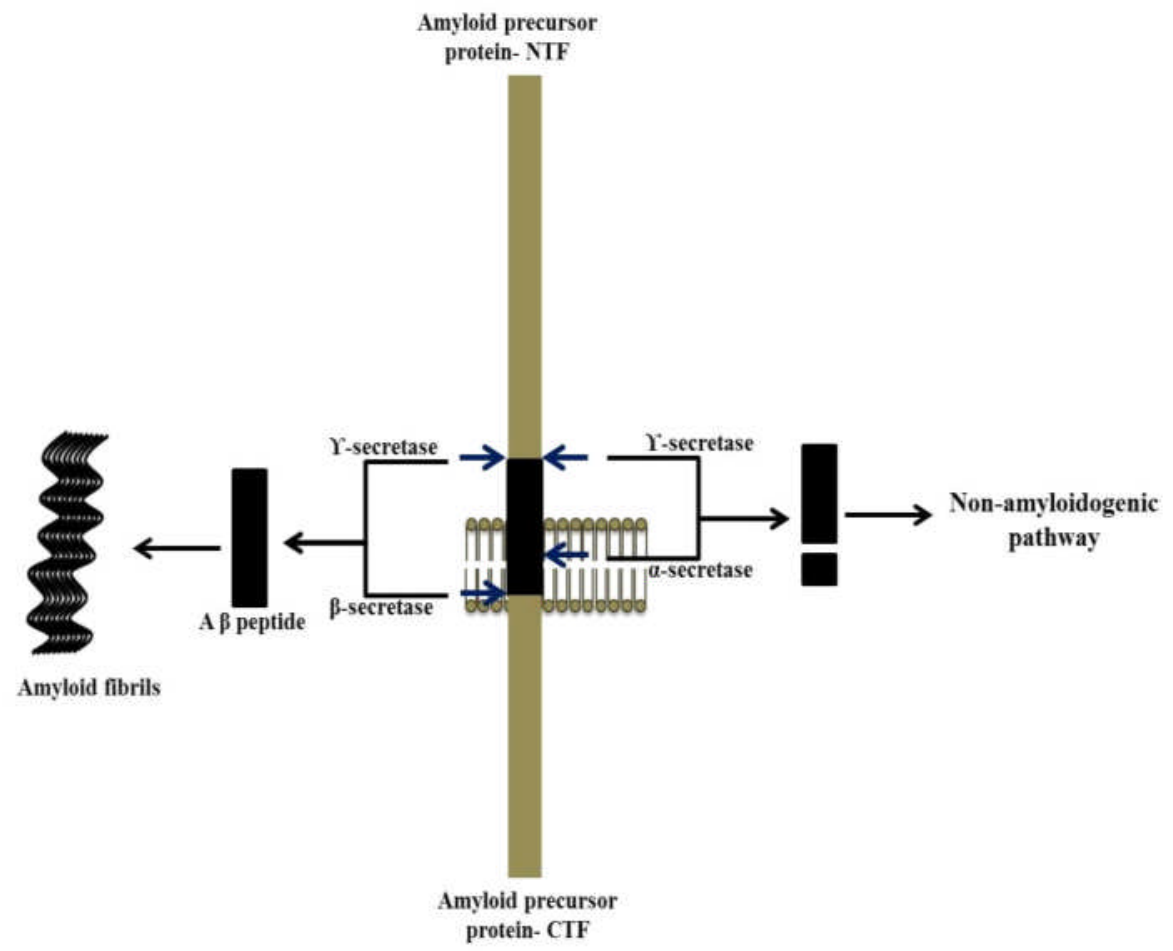

Figure 2 


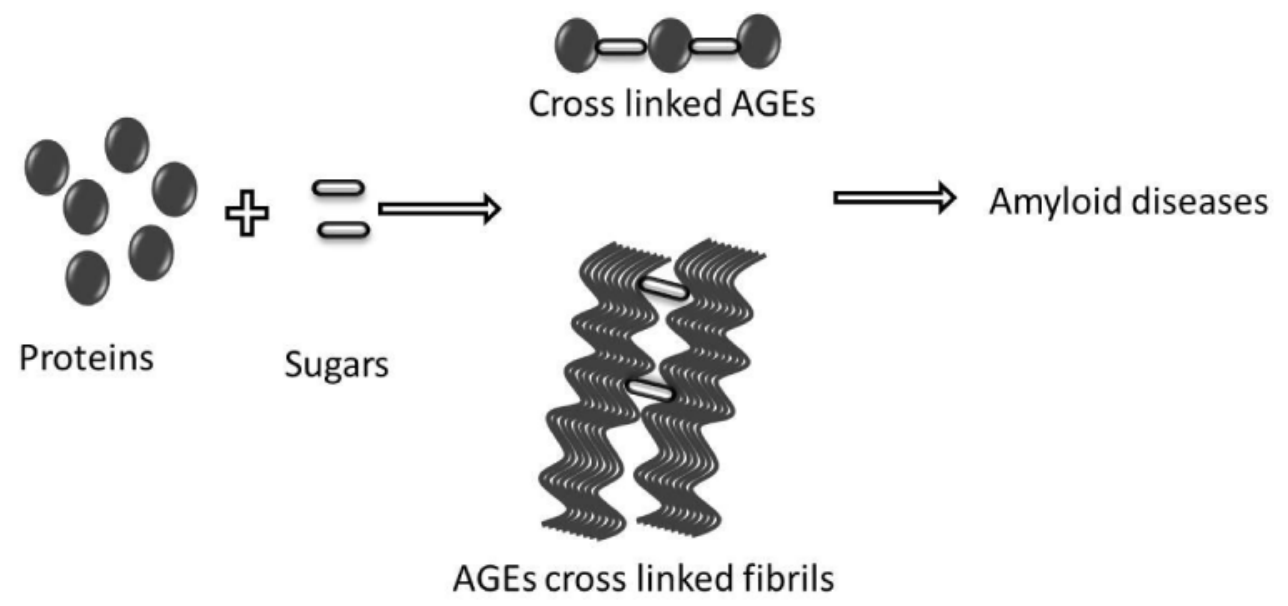

Figure 3 


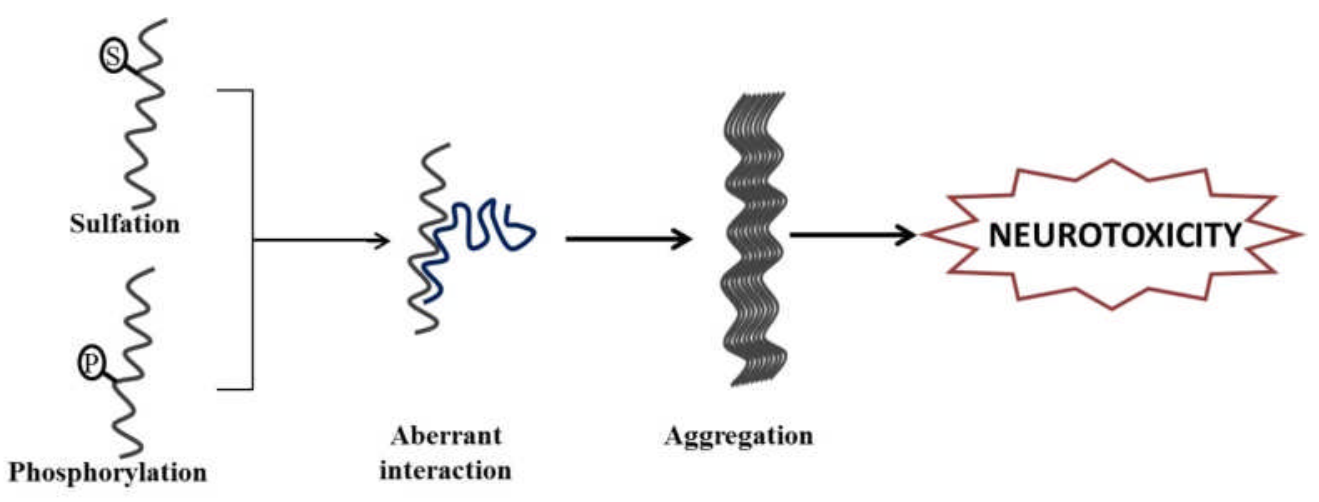

Figure 4 


\section{Highlights}

- In protein misfolding, protein molecules acquire wrong tertiary structure thereby promoting aggregation that lead to many protein misfolding diseases.

- Protein misfolding occurs because of changes in environmental conditions, dominant negative mutations, error in post-translational modifications,error in degradation, oxidative stress, and trafficking error.

- Several novel therapeutic approaches have been in vented that partly cured or reversed the pathological state.

- A novel therapeutic approach employs nanobodies that targets multisteps in fibril formation pathway thus may possibly completely cure these misfolding diseases. 
Table. 1 Structures of different drugs for treating misfolding diseases

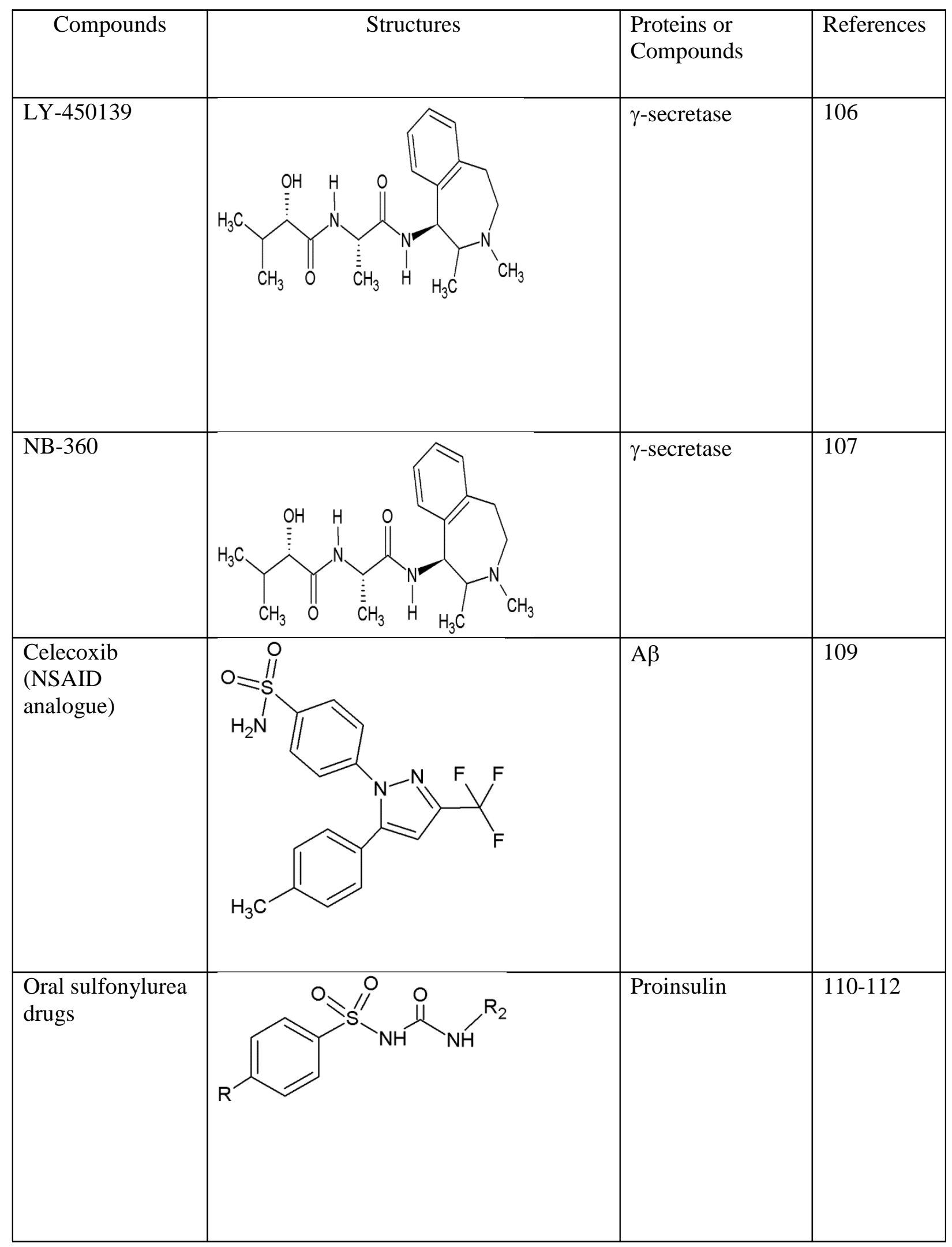




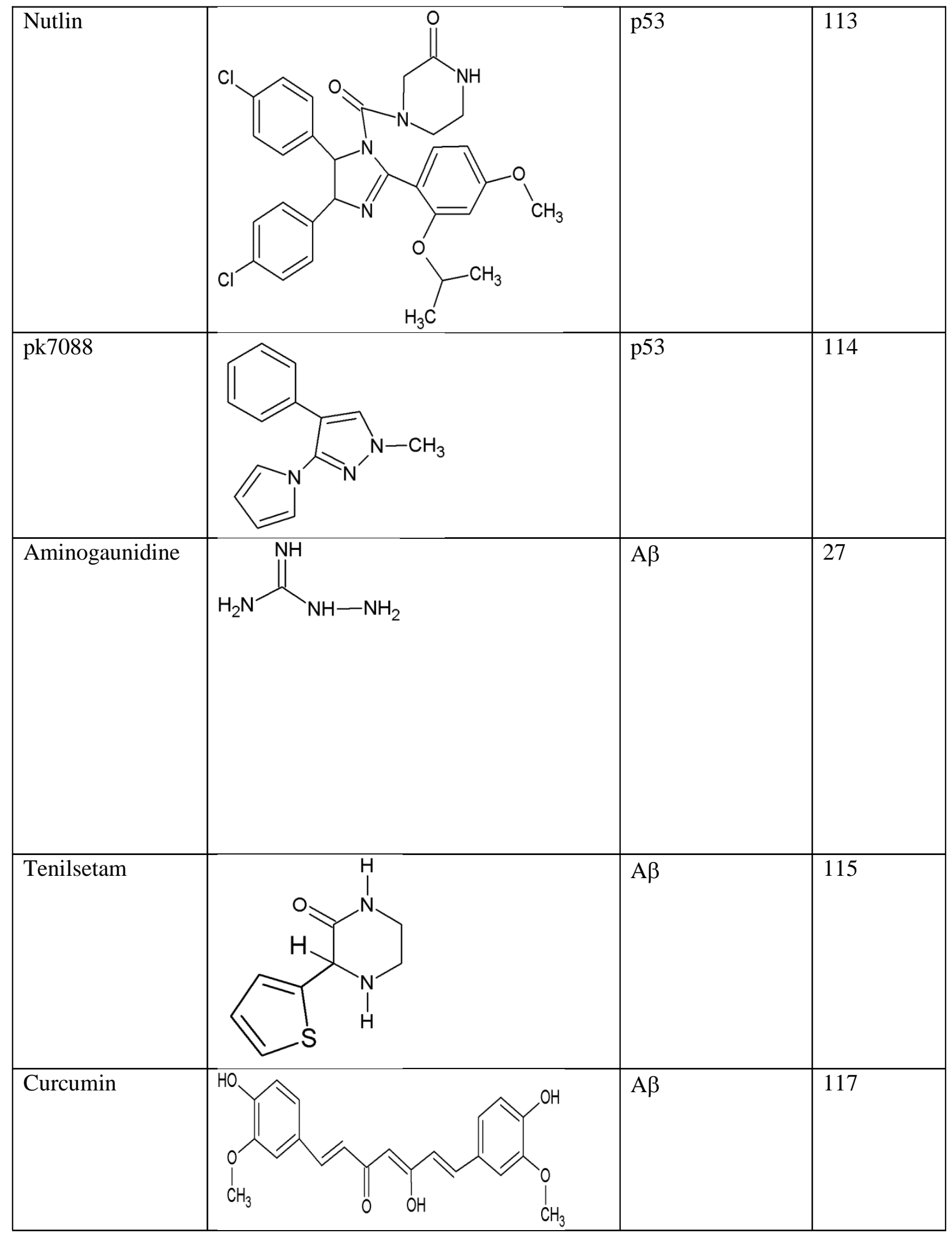




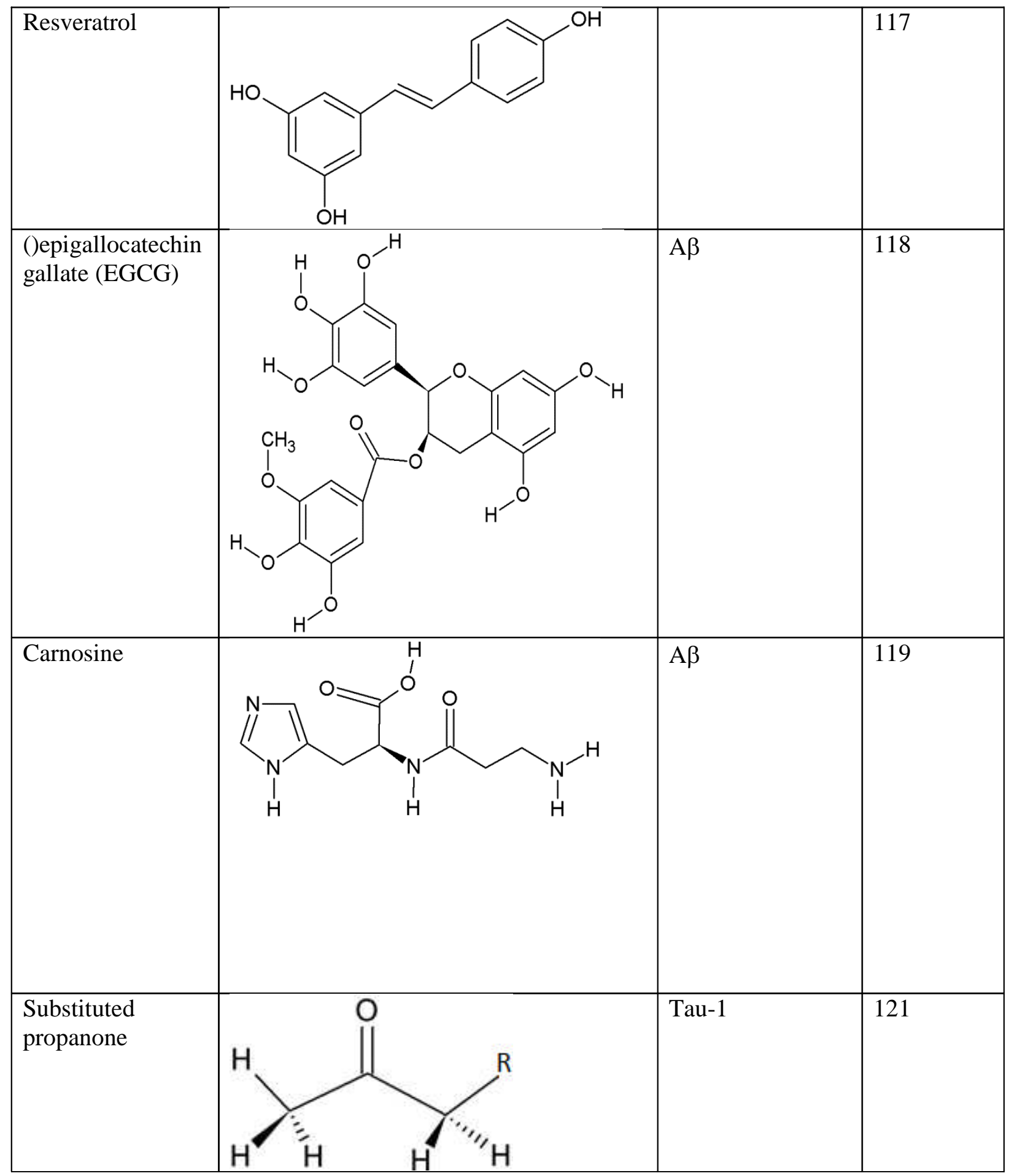




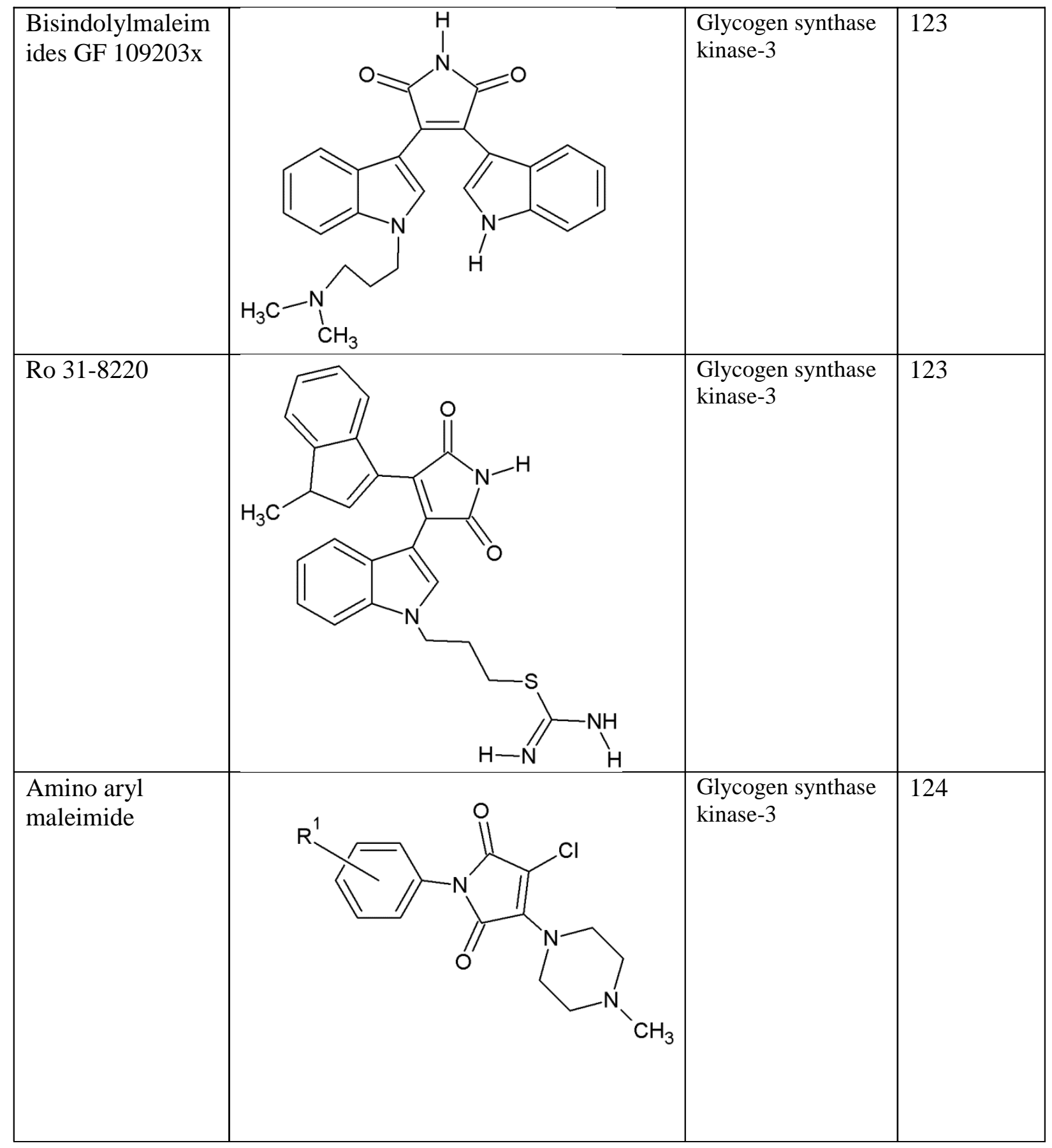




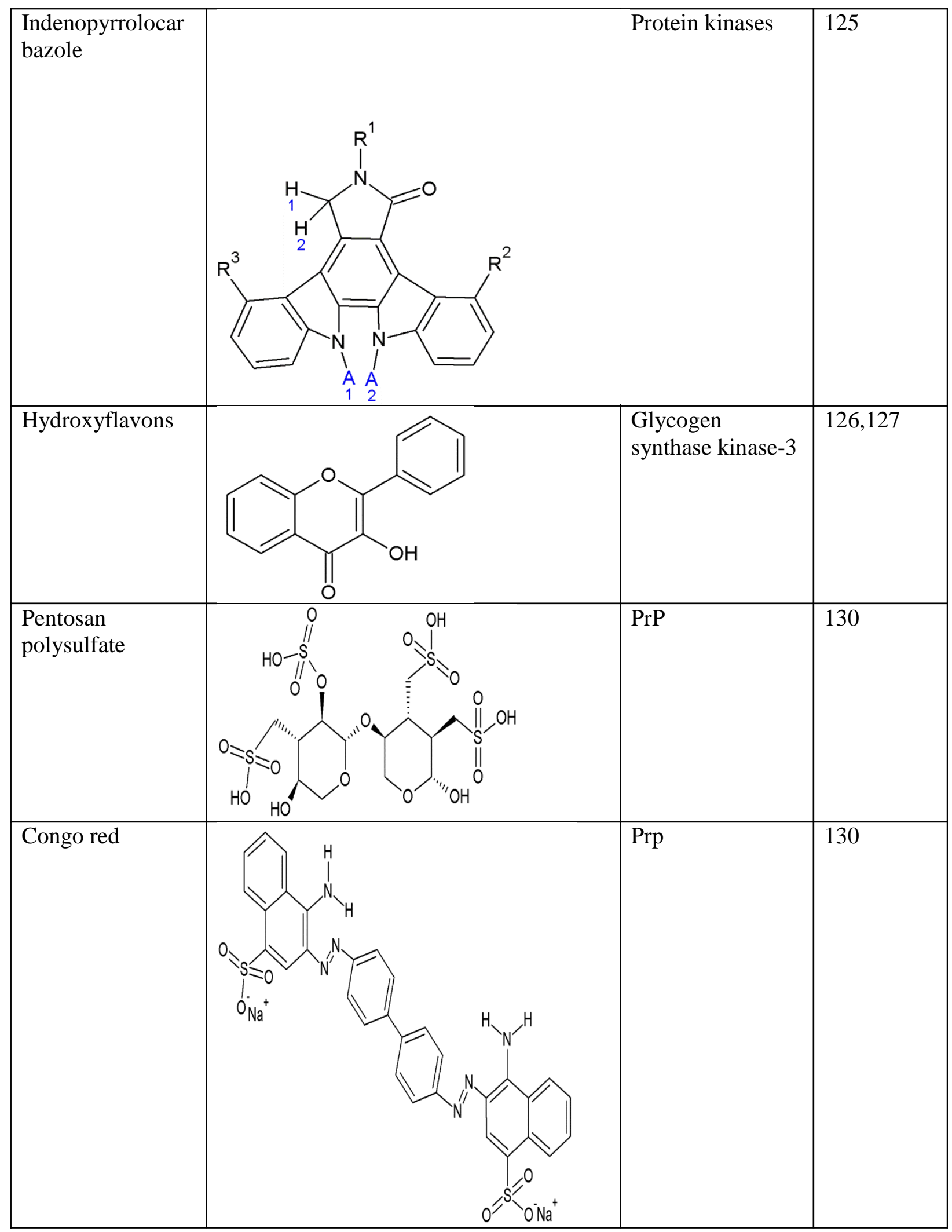




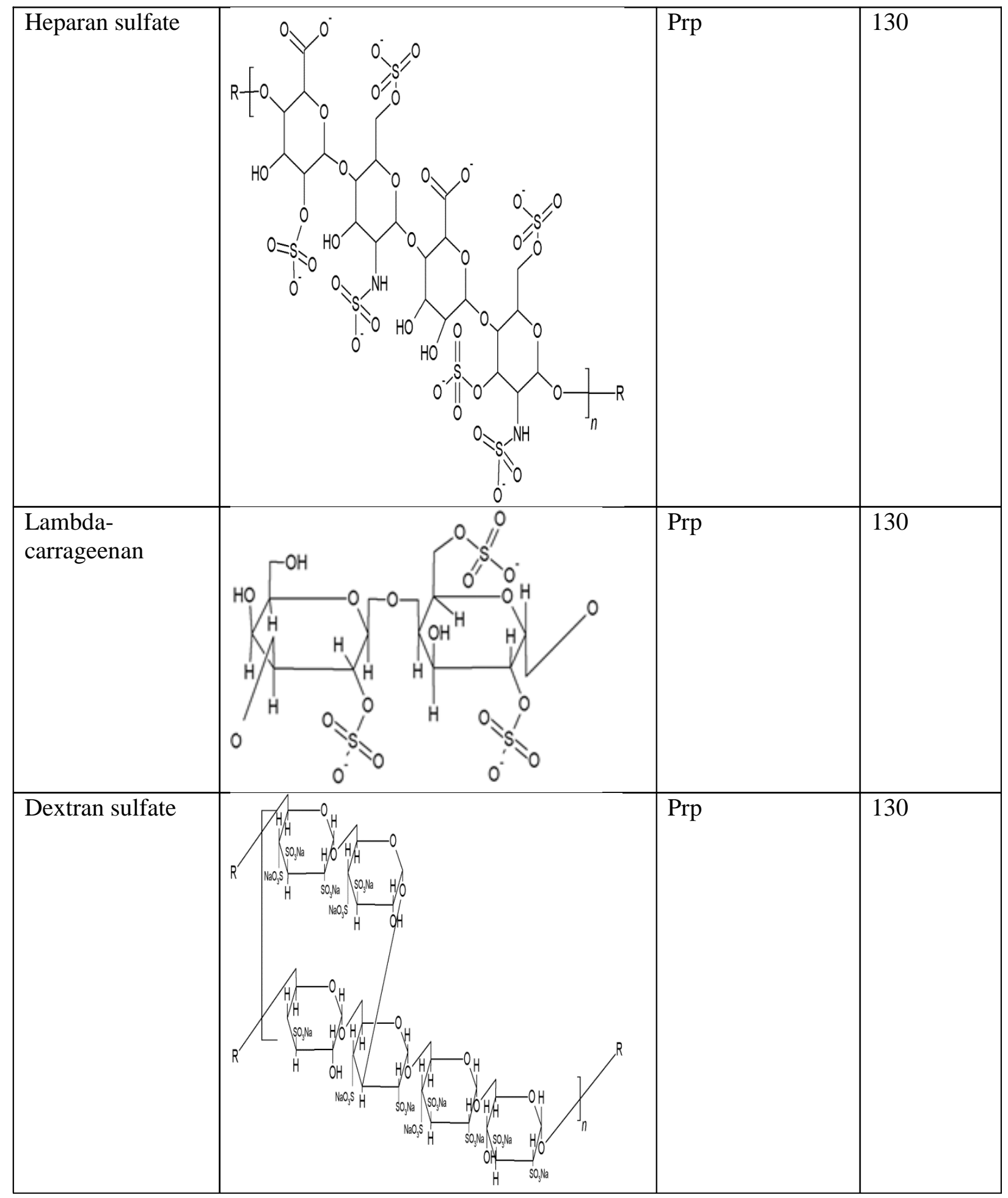




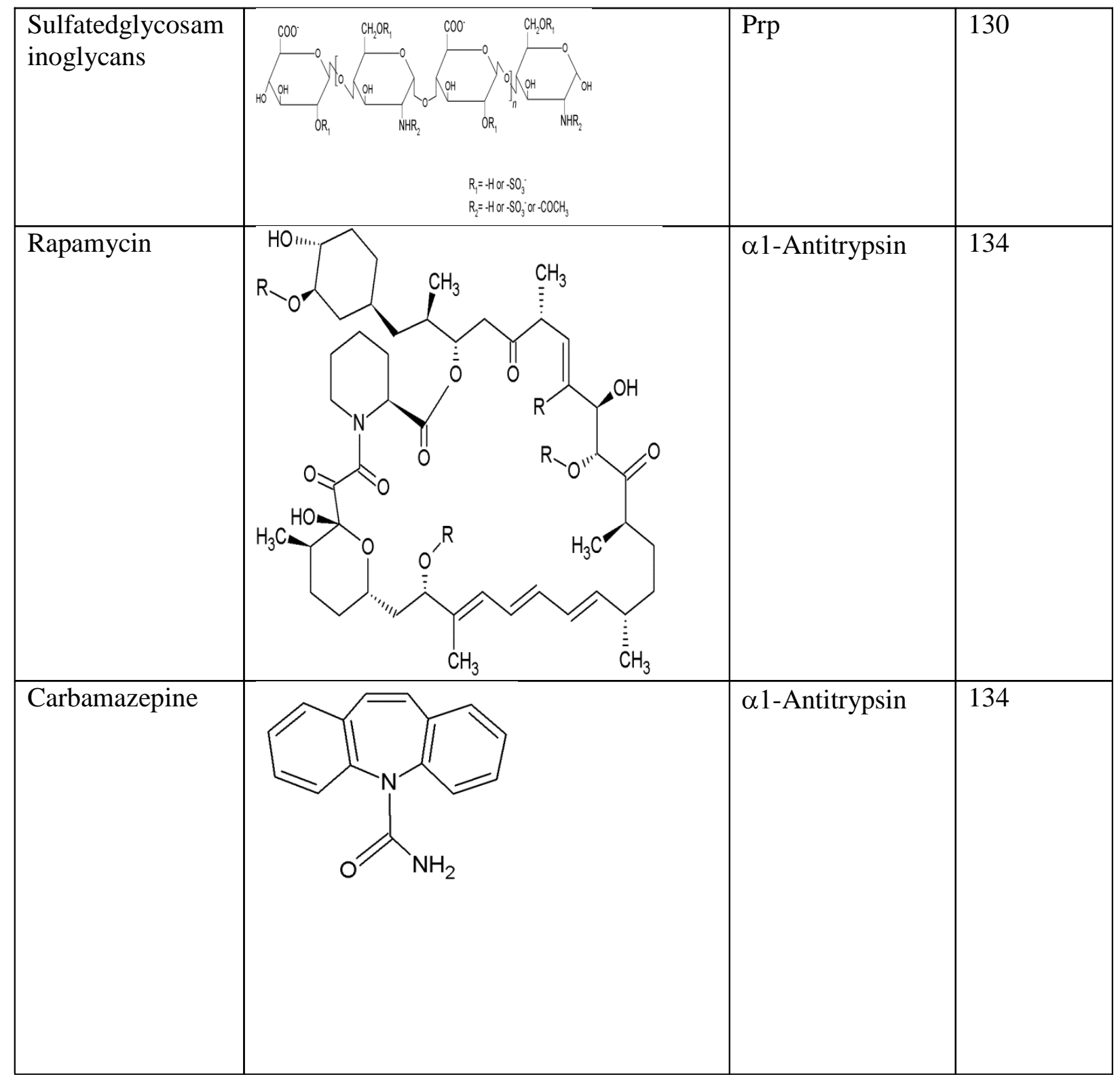




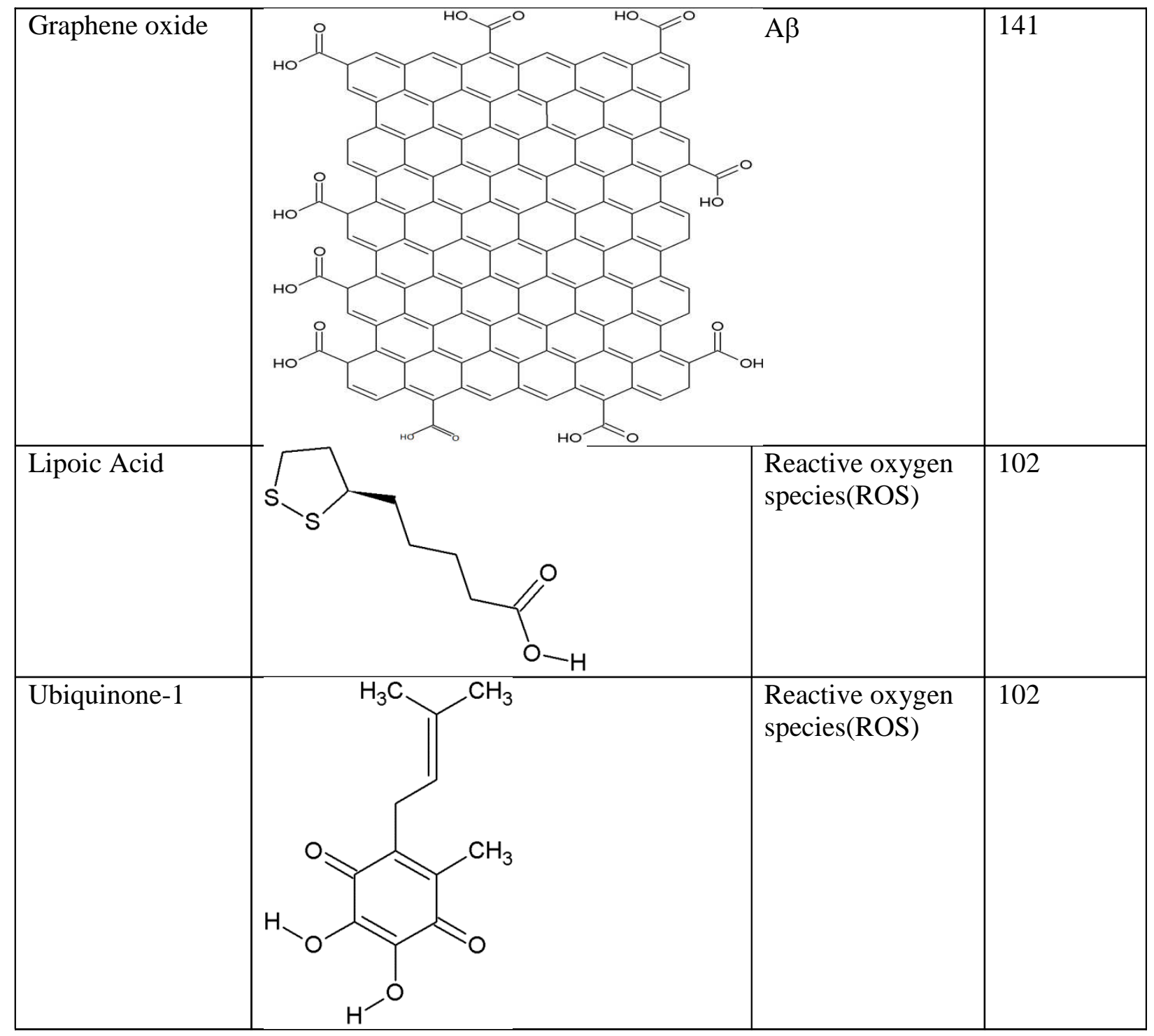




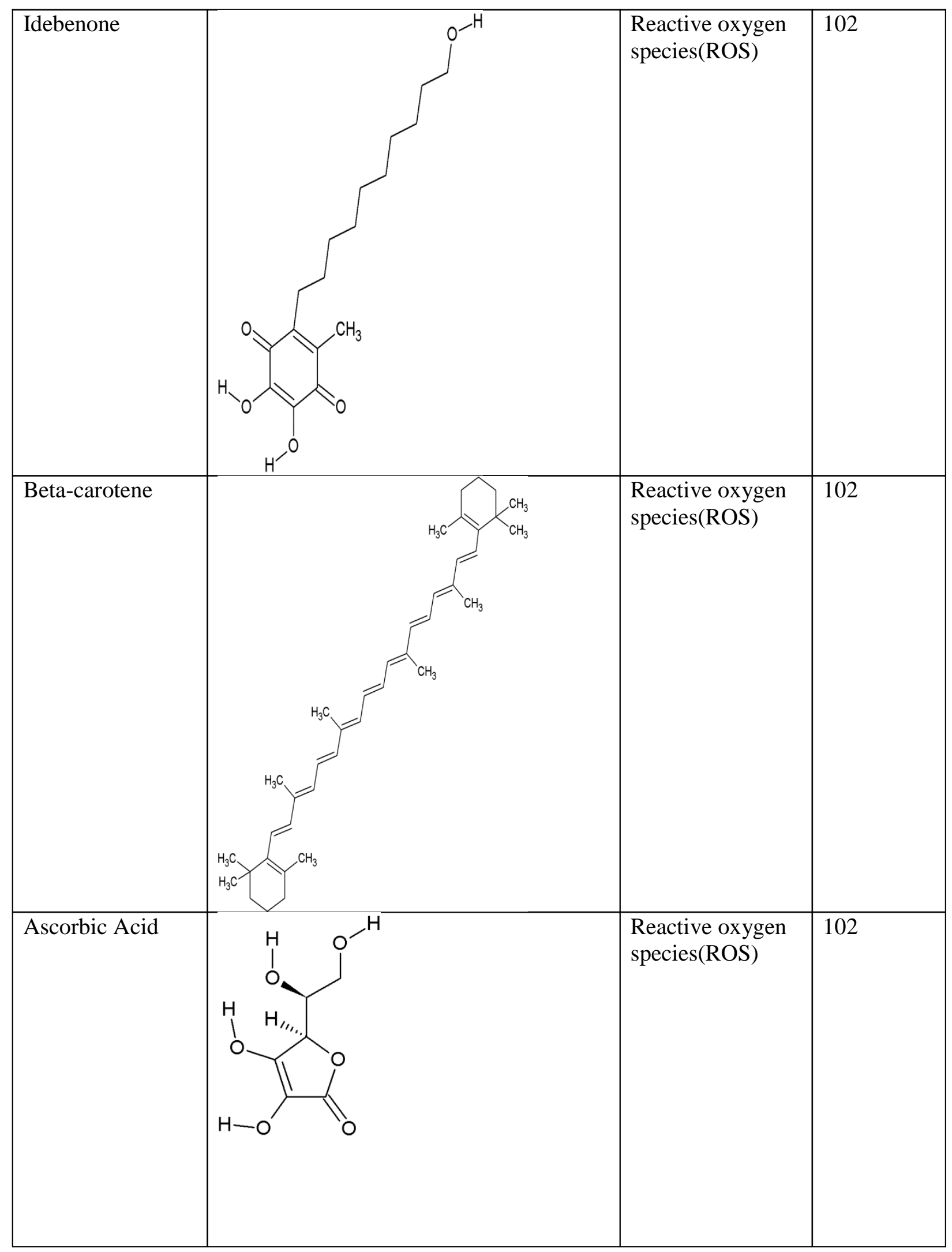




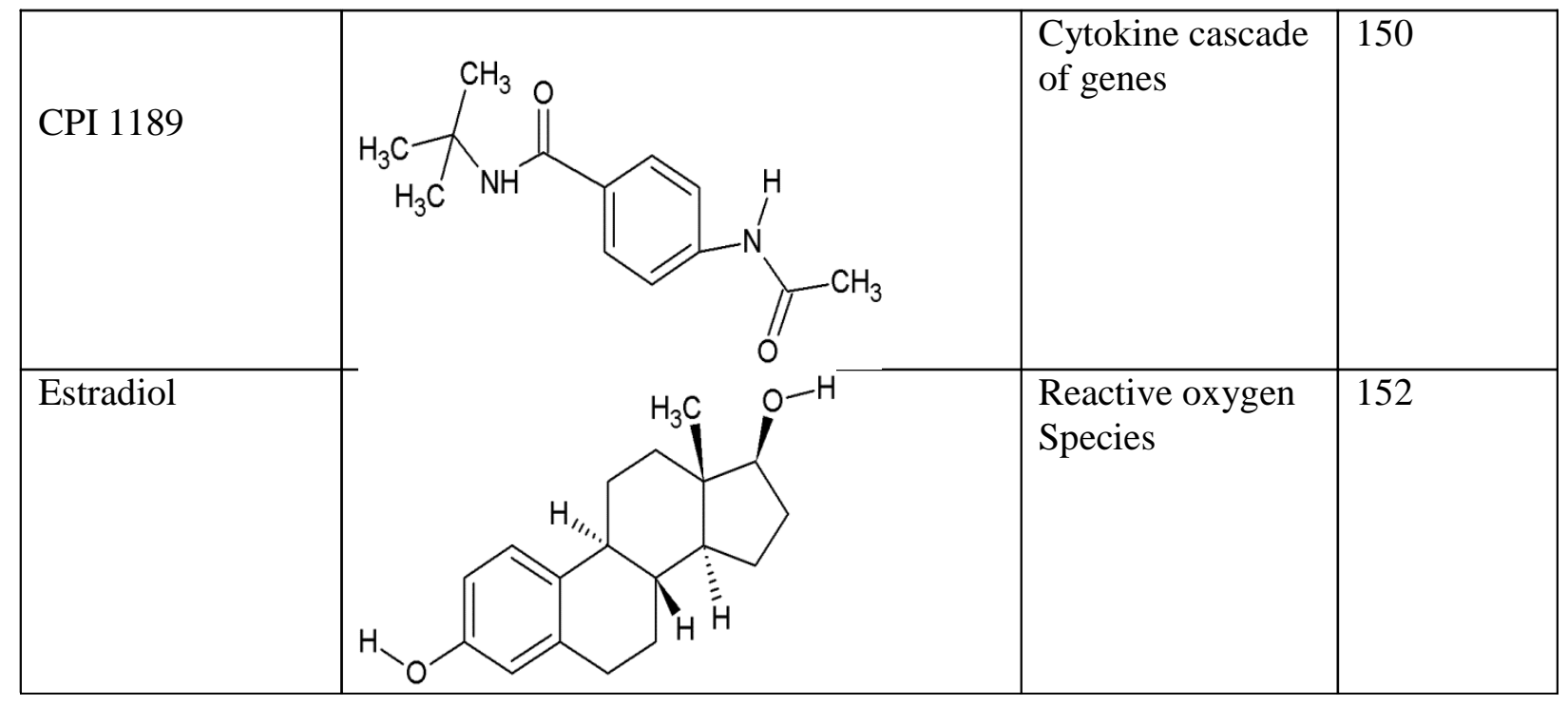

